[This document contains the author's accepted manuscript. For the publisher's version, see the link in the header of this document.]

\title{
An Expert System Approach to Audit Planning and Evaluation in the Belief- Function Framework
}

\author{
By Rajendra P. Srivastava, Saurav K. Dutta, Robert W. Johns \\ The University of Kansas, Rutgers University, Zale Lipsy University Hospital
}

\section{Paper citation:}

Srivastava, Rajendra. (1996) An Expert System Approach to Audit Planning and Evaluation in the Belief-Function Framework. International Journal of Intelligent Systems in Accounting, Finance and Management, 5 (3), 165-183. 
International Journal of Intelligent Systems in Accounting, Finance and Management, Vol. 5, No. 3, 1996, pp. 165-183.

\title{
An Expert System Approach to Audit Planning and Evaluation in the Belief-Function Framework\#
}

\author{
Rajendra P. Srivastava \\ Ernst \& Young Professor of Accounting \\ School of Business, University of Kansas \\ Lawrence, Kansas 66045-2003 \\ Saurav K. Dutta \\ Assistant Professor \\ Graduate School of Management \\ Rutgers University-Newark \\ Newark, N.J. \\ and \\ Robert W. Johns*, CPA, FHFMA \\ Zale Lipsy University Hospital \\ 5151 Harry Hines Blvd. \\ Dallas, Texas 75235
}

Director, Center for Auditing Research and Advanced Technology

July 1996

The authors would like to thank Peter Gillett, Keith Harrison, and Prakash Shenoy for their insightful comments on the paper.

* Formerly with a Big Six public accounting firm, worked for 11 years auditing health care units. 


\section{An Expert System Approach to Audit Planning and Evaluation in the Belief-Function Framework}

\section{INTRODUCTION}

This article has two main related objectives. The first objective is to show how the strength of evidence can be represented in belief functions. The situation where one item of evidence relates to more than one audit objective or account is of special interest here, particularly the evidence that provides different levels of support to different audit objectives or accounts. The second objective is to demonstrate the use of Auditor's Assistant ${ }^{1}$ (an expert system shell to automate the belief functions propagation in networks) for planning and evaluation of an audit and to perform a sensitivity analysis of the audit program. Also, we discuss how sensitivity analysis can help plan an efficient audit. For the second objective, we use the actual audit program of a Big Six audit firm for the accounts receivable balance of a health care unit. We chose a health care unit because it provides a fairly complex situation for testing Auditor's Assistant. A brief introduction to Auditor's Assistant is presented in Appendix.

In recent years, there has been a significant level of activity in the artificial intelligence and expert systems area for audit decisions both by academics and practitioners (Vasarhelyi 1990, Vasarhelyi and Srinidhi 1993, 1995; see also Boritz and Wensley 1990, 1992; Chandler 1985; Gillett 1993; Hansen and Messier 1982, 1986a, 1986b; Leslie et al. 1986). The following systems have been developed, in particular, for planning and evaluation of an audit: ADAM developed by Clarkson Gordon (Leslie et al. 1986), ADAPT by Grant Thornton (Gillett 1993), and CAPEX by Boritz and Wensley (1992).

Moreover, there are several expert systems that are currently being used by the Big Six accounting firms in their audit and tax practices. These systems are used to generate specific audit programs, evaluate internal controls, assess the risk of fraud, advise on tax related issues, and assess the potential for bankruptcy and going concern issues. For a detailed reference on these expert systems, see Brown and O’Leary (1993).

There are two important issues in planning and evaluation of an audit. One is the structure of audit evidence and the other is the representation of uncertainties associated with the audit evidence. SAS 
Srivastava, Rajendra. (1996) An Expert System Approach to Audit Planning and Evaluation in the Belief-Function Framework. International Journal of Intelligent Systems in Accounting, Finance and Management, 5 (3), 165-183. Publisher's Official Version: <http://onlinelibrary.wiley.com/journal/10.1002/\%28ISSN\%291099-1174>. Open Access Version: <http://kuscholarworks.ku.edu>.

No. 47 (AICPA 1983) uses a simple structure ${ }^{2}$ of the audit evidence and treats risks as probabilities (Srivastava and Shafer 1992). However, audit evidence, in general, forms a network (see, e.g., Arens and Loebbecke 1994, Dutta and Srivastava 1992, Srivastava and Shafer 1992). In a network, one item of evidence may provide support to more than one audit objective of an account or to more than one account. For example, the confirmation of accounts receivable provides support to the existence and accuracy objectives of the account.

The auditing profession has treated uncertainty associated with audit evidence in terms of probabilities. Several researchers, however, argue that the belief-function framework ${ }^{3}$ provides a better representation for such uncertainties (e.g., see Akresh, Loebbecke and Scott 1988; Shafer and Srivastava 1990). Recently, Srivastava and Shafer (1992) have discussed the problems with interpreting audit risk as probability and have provided a belief-function interpretation of the risk which is more intuitive than the interpretation provided by the probability model.

The three systems mentioned earlier do incorporate the structure of the audit evidence in their treatments. However, they ignore the interdependencies among the evidence, and hence ignore the network structure. ADAM uses probability to represent uncertainty and the basic probability rules to combine the evidence. ADAPT has the options of using probability or belief functions for representing uncertainty, and it uses the corresponding schemes along with certain heuristic rules for combining evidence. Similar to ADAM, the system developed by Boritz and Wensley (1990) uses probability to represent uncertainty. However, the Boritz and Wensley system uses heuristic rules instead of probability rules to combine the evidence. Irrespective of the framework used for representing uncertainty, these systems do not take advantage of the full strength of the evidence because they ignore interdependencies among the evidence, i.e., the network structure. For example, if confirmation of accounts receivable provides 0.8 level of assurance to the two objectives: existence and valuation, and if the two items of evidence are assumed to be independent then the combined assurance will be only 0.64. However, if the two are treated as interdependent then the total assurance will be 0.8 in either representation (probabilities or belief functions, see, e.g., Srivastava and Shafer 1992). 
Srivastava, Rajendra. (1996) An Expert System Approach to Audit Planning and Evaluation in the Belief-Function Framework. International Journal of Intelligent Systems in Accounting, Finance and Management, 5 (3), 165-183. Publisher's Official Version: <http://onlinelibrary.wiley.com/journal/10.1002/\%28ISSN\%291099-1174>. Open Access Version: <http://kuscholarworks.ku.edu>.

In the present paper, the belief-function framework is used to represent uncertainty. Since the general structure of the audit evidence is a network, combining the audit evidence in such a network becomes a task of propagating beliefs through the network. Since the belief function calculus becomes very complex for network structures, a computer program is essential for propagating beliefs in such structures. There are three computer programs currently available for propagating belief functions in networks: (1) DELIEF developed by Zarley, Hsia and Shafer (1988), (2) Auditor's Assistant developed by Shafer, Shenoy and Srivastava (1988), and (3) Pulcinella developed by Saffiotti and Umkehrer (1991). One advantage of Pulcinella is that it can propagate uncertainty in networks under the following frameworks: belief functions, probability theory, Boolean algebra, and possibility theory. However, in our opinion, Auditor's Assistant is more user-friendly than DELIEF or Pulcinella. Therefore, we will use Auditor's Assistant to show how one can use an expert's knowledge to plan and evaluate an audit. All the systems above use the work by Shenoy and Shafer $(1986,1990)$ on propagating uncertainty through networks using local computations. We will not compare or contrast the three systems in this article.

Auditor's Assistant provides an interactive tool for developing a comprehensive audit risk model for audit decisions. It allows the user to draw the evidential network relevant to the situation and to map relationships among the audit objectives, accounts, and the audit evidence that are appropriate for the engagement. Also, it allows the user to input the desired or achieved level of assurance associated with the audit evidence related to a given variable. Variables in the network represent various audit objectives of an account or various accounts in the financial statements to be audited. The system aggregates all the evidence to provide an overall belief for each variable in the network.

The remainder of the article is divided into four sections and an appendix. Section 2 discusses an approach to representing the strength of evidence under the belief-function framework. Section 3 demonstrates the use of Auditor's Assistant for planning and evaluation of the audit of the accounts receivable balance of a health care unit. Section 4 discusses the results of a sensitivity analysis for determining the impact of various items of evidence on the overall assurance. Section 5 provides a summary and conclusion, describes some future research problems, and highlights the limitations of the 
Srivastava, Rajendra. (1996) An Expert System Approach to Audit Planning and Evaluation in the Belief-Function Framework. International Journal of Intelligent Systems in Accounting, Finance and Management, 5 (3), 165-183. Publisher's Official Version: <http://onlinelibrary.wiley.com/journal/10.1002/\%28ISSN\%291099-1174>. Open Access Version: <http://kuscholarworks.ku.edu>.

study. Finally, Appendix discusses the use of Auditor's Assistant to draw the evidential network from the knowledge of the audit engagement. In addition, we discuss how to construct various relationships among the variables of the network.

\section{STRENGTH OF EVIDENCE IN BELIEF FUNCTIONS}

As mentioned earlier, in general, the audit evidence forms a network of variables; variables being the audit objectives, accounts, and the financial statement as a whole. The network structure is formed because certain items of evidence bear on more than one variable. In order to determine whether the account balance is fairly stated or the financial statements are fairly presented, the auditor must combine all the evidence accumulated in the audit process. For this purpose, the auditor must assess the strength of each piece of evidence. Our goal here is to show how such assessments can be represented in terms of belief functions.

\section{Evidence Bearing on One Variable}

The representation of the strength of evidence bearing on one variable is straightforward. Consider the following situation. The auditor has evaluated the evidence and concluded, based on professional judgment, that the evidence provides a medium level of support, say 0.6 on a scale $0-1$, that assertion $\mathrm{X}$ is met (' $\mathrm{x}$ ') and no support for its negation (' $\sim \mathrm{X}$ '). One can express this judgment in terms of belief functions as $\operatorname{Bel}(\mathrm{x})=0.6$, and $\operatorname{Bel}(\sim \mathrm{x})=0$. This can be expressed in terms of $\mathrm{m}$-values ${ }^{4}$ (basic probability assignment function) as $\mathrm{m}(\mathrm{x})=0.6, \mathrm{~m}(\sim \mathrm{x})=0$, and $\mathrm{m}(\{\mathrm{x}, \sim \mathrm{x}\})=0.4$. These $\mathrm{m}-$ values suggest that the auditor has (1) direct evidence that the assertion is true (i.e. ' $\mathrm{x}$ ' is true) with 0.6 degree of support, (2) no evidence that the assertion is not true ( $~ \sim x$ '), and (3) 0.4 degree of uncommitted support.

Consider now a different situation. The auditor has evaluated that the evidence is negative. That is, the evidence supports ' $\sim \mathrm{x}$ ', the negation of the assertion, say, at 0.3 level, and there is no support for ' $\mathrm{x}$ ' that the assertion is met. This feeling can be expressed as: $\mathrm{m}(\mathrm{x})=0, \mathrm{~m}(\sim \mathrm{x})=0.3$, and $\mathrm{m}(\{\mathrm{x}, \sim \mathrm{x}\})=0.7$. There are situations where the auditor might have several items of evidence, some might be positive and some negative. Rather than evaluating individually the level of support from each 
item of evidence, the auditor may make an intuitive judgment about the overall strength of the combined evidence. Suppose the auditor's combined evaluation of all the evidence pertinent to this assertion is that ' $\mathrm{x}$ ' is true with a medium level of support, say, 0.4, ' $\sim \mathrm{x}$ ' is true with a low level of support, say, 0.1 . This feeling can be expressed as: $\mathrm{m}(\mathrm{x})=0.4, \mathrm{~m}(\sim \mathrm{x})=0.1$, and $\mathrm{m}(\{\mathrm{x}, \sim \mathrm{x}\})=0.5$. We can not express easily such feelings using probabilities.

\section{Evidence Bearing on More Than One Variable}

Invariably, on every audit, the auditor collects several items of evidence that bear on more than one variable. For example, confirmations of accounts receivable balance from the customers provide support to both 'Existence' and 'Accuracy' objectives. The level of support may vary. For instance, the auditor may decide that the evidence provides a high level of support, say 0.9 , to ' $\mathrm{e}$ ' that the 'Existence' objective is met and a medium level of support, say 0.6, to 'a' that 'Accuracy' objective is met. This judgment can be expressed in terms of belief functions as: $\operatorname{Bel}(\mathrm{e})=0.9, \operatorname{Bel}(\sim \mathrm{e})=0, \operatorname{Bel}(\mathrm{a})=$ 0.6, and $\operatorname{Bel}(\sim a)=0$. This aspect of the judgment is easy and intuitive. However, we need to express the above judgment in terms of $m$-values in order to combine various items of evidence using Dempster's rule. Since all the beliefs above come from the same evidence, the confirmation of accounts receivable, we need to convert these beliefs into m-values on the joint space of the two variables ( $\{\mathrm{e}, \sim \mathrm{e}\} \mathrm{x}\{\mathrm{a}, \sim \mathrm{a}\})$. This task of converting individual beliefs to $\mathrm{m}$-values on the joint space is not trivial. Dubois and Prade (1986, 1987, see also 1992, and 1994) have discussed a formal approach to determining the m-values on the joint space. Recently, Srivastava and Cogger (1995) have developed a heuristic algorithm that determines $m$-values on the joint space of the variables from the beliefs defined on each variable. For simple situations where the evidence is either positive or negative, Shafer's approach (1976) of using nested m-values ${ }^{5}$ is easier to use. Using Shafer's approach, we obtain:

$$
\begin{gathered}
\mathrm{m}(\{\text { ea }\})=0.6, \\
\mathrm{~m}(\{\text { ea, e } \sim \mathrm{a}\})=0.3, \\
\mathrm{~m}(\{\text { ea }, \sim \mathrm{ea}, \mathrm{e} \sim \mathrm{a}, \sim \mathrm{a} \sim \mathrm{e}\})=0.1 .
\end{gathered}
$$


The traditional approach of representing uncertainties using probabilities demands much more detailed information in terms of conditional probabilities to represent the strength of support in situations where one item of evidence bears on many variables. Using belief functions, we can model the auditor's judgments of the individual beliefs in terms of $m$-values on the joint space. This approach becomes important when we want to model dependent items of evidence. As suggested in the introduction, if dependent items of evidence are not treated properly, it will lead to an inefficient audit.

\section{PLANNING AND EVALUATION OF AUDIT USING AUDITOR'S ASSISTANT}

The main purpose of this section is to demonstrate the use of Auditor's Assistant in planning and evaluation of the audit of the accounts receivable balance of a health care unit. Figures 1-4 represent the evidential network as perceived by one of the authors who has substantial experience 6 in the industry. All the procedures used in Figures 1-4 are taken from an actual audit program of a Big Six audit firm (A copy of the program is available from the authors on request).

The question whether Figures 1-4 represent the correct mapping of the audit evidence is not important here; it is a question that needs to be answered but in a separate study. Here, our purpose is to demonstrate the use of Auditor's Assistant in a complex setting for determining whether the plan of audit is adequate to achieve the desired level of assurance that the account is fairly stated.

-- Figures 1-4 here --

In the present example, the auditor assumes that he cannot rely on transaction processing controls and thus would like to obtain a sufficient degree of assurance from substantive tests. As Figure 1 shows, a variable node on the far left represents the accounts receivable account. The relevant audit objectives for the account in this case are: Existence and Occurrence, Completeness, Accuracy and Valuation, and Presentation and Disclosure. Since we are assuming that the accounts receivable balance is fairly stated if and only if all the audit objectives have been met, nodes representing the four audit objectives should be connected to the node representing the accounts receivable account through an 'and' node. However, Auditor's Assistant runs very efficiently if we build the network by connecting only two nodes representing sub-goals to the node representing the main goal. Thus, for efficient computations, we first connect nodes representing 'AR Existence \& Occurrence' and 'AR 
Srivastava, Rajendra. (1996) An Expert System Approach to Audit Planning and Evaluation in the Belief-Function Framework. International Journal of Intelligent Systems in Accounting, Finance and Management, 5 (3), 165-183. Publisher's Official Version: <http://onlinelibrary.wiley.com/journal/10.1002/\%28ISSN\%291099-1174>. Open Access Version: <http://kuscholarworks.ku.edu>.

Completeness' to an intermediate node 'E\&O\&C' through an 'and' node. Similarly, we connect nodes representing 'AR Accuracy \& Valuation' and 'Presentation \& Disclosure' to an intermediate node 'A\&V\&P' through an 'and' node. These intermediate nodes are then connected to the accounts receivable node through an 'and' node. All other 'and' relationships involve only two sub-goals. Creation of these intermediate nodes for an efficiency purpose does not affect the original relationship between the account and its audit objectives.

The number or a set of numbers in the evidence box (see Figures 1-4) represents the input mvalues. In the case where we have only one number, the number represents the level of support that the variable is met or the set of variables are met if the evidence is connected to more than one node. For example, in Figure 1, the evidence 'Third Party Utilization Reviewed (AR7)' provides 0.4 degree of support to 'Accounts Rec.' that it is met, and the evidence 'Historical Info. (IF)' provides 0.4 degree of support to two variables 'AR Existence \& Occurrence' and 'AR Completeness' that they are met.

In the case where an item of evidence is connected to more than one variable and the evidence provides a different level of support to each variable then the evidence box would contain more than one number. For example, the evidence 'Third Party Reviews of Charges (AR1)' provides 0.8 degree of support to 'Prospective Payors' and 0.4 degree of support to 'Charge Payors'. One can use the nested m-values to input the support for such an item of evidence (see Footnote 5 for details). These values are based upon the auditor's judgment of the audit procedure he or she has performed (or would perform) and the outcome (or expected outcome) of the procedure. It should be noted that the display of the level of support in Figure 1 in cases similar to the above is somewhat modified from the actual display in Auditor's Assistant. The display in Auditor's Assistant is in terms of nested m-values. However, for the convenience of readers we have expressed the level of support in terms of individual beliefs to various objectives.

In the present article, the judgment of one auditor is used to illustrate the process. However, empirical research is needed to establish the guidelines for determining the level of support obtained from various items of evidence. As academicians, we might feel uncomfortable asking for such a judgment from the auditor. But we know of several big audit firms that do require their auditors to 
make judgments about the level of assurance they believe they have obtained from a given item of evidence in terms of the 'risk factor' $\lambda$ where $\lambda$ is the Poisson parameter. $\lambda=3.0$ indicates a confidence level of 0.95 given that no error was expected in the population (see, e.g., Leslie, Aldersley, Cockburn, and Reiter 1986). Moreover, they make judgment on $\lambda$ for each item of evidence and then combine them to obtain the overall risk factor for the audit objective.

The numbers in a variable node represent the output beliefs. The first number represents the belief that the variable in the node is met and the second number represents that the variable is not met. For example, in Figure 1, 'Accounts Rec.' node, has '0.957; 0'. The first number 0.957 means that based on all the evidence gathered by the auditor (as shown in the network) the overall belief that the accounts receivable balance is fairly stated is 0.957 . The second number 0 means that based on the evidence, there is no belief that the account balance is materially misstated.

The present example has been developed for a hypothetical client in the health care industry in which one of the authors has a significant experience as an auditor. The assumptions made in the example regarding the structure of the audit evidence and the level of support from each item of evidence are based on the experience of the auditor. We have used Auditor's Assistant in the present example to test whether an adequate audit has been conducted or will be conducted if we obtain the planned level of support from each item of evidence. Auditor's Assistant provides an objective way to aggregate all such items of evidence with all the interdependencies (i.e., keeping the network structure of the audit evidence). It is not possible to develop an optimization scheme for audit procedures in an audit because the problem is a np complete (complex) problem. Research efforts are needed to develop heuristics for determining efficient and affective audit programs.

If the items of evidence depicted in the network do provide the planned level of support then the auditor will achieve the desired, say 0.95 , level of overall support that the accounts receivable balance is fairly stated. However, if some items of evidence do not provide as much support as planned then the auditor can use Auditor's Assistant to determine which combination of evidence is the best in terms of cost saving to achieve the desired level of overall support. This may involve from proposing an 
adjusting entry and subsequently modifying the belief to performing extended tests or collecting new items of evidence.

\section{SENSITIVITY ANALYSIS}

This article performs two kinds of sensitivity analysis. One determines the effects of the location of evidence in the network on the variables in the network. The other deals with the effects of variations in the auditor's judgment of the strength of evidence on the overall belief on each variable in the network. Both analyses have practical implications as discussed below.

\section{Effects of Location of Evidence in the Network on the Overall Belief}

The effects of various items of evidence on different objectives at different levels in the network are discussed here. All the relationships among various variables are represented in terms of an 'and' node. Thus, because of such relationships among variables, any positive support to the main objective will propagate in its full strength to all its sub-objectives. For example, the evidence 'Third Party Utilization Reviewed (AR7)' provides 0.4 degree of support that 'Accounts Rec.' objective is met. This support will propagate through the network to all the sub-objectives and sub-sub-objectives. In other words, 'Third Party Utilization Reviewed (AR7)', while providing a direct support of 0.4 degree to 'Accounts Rec.', provides an indirect support of 0.4 to all other variables in the network.

However, in the case of a negative item of evidence at the main objective, the flow of the strength to sub- and sub-sub-objectives in the net work depends on the evidence at these sub-, and sub-subobjectives. For example, in the absence of any other item of evidence in the network, a negative support of say 0.4 at 'Accounts Rec.' will propagate zero level of support to all its sub-objectives and sub-sub-objectives. This makes intuitive sense. If we know that 'Accounts Rec.' is not fairly stated then we cannot say which of the four sub-objectives ('AR Existence \& Occurrence', AR Completeness', AR Accuracy \& Valuation', and 'Presentation \& Disclosure') is met or is not met. However, the situation changes with some information on the other sub-objectives. For example, if we know that 'AR Existence \& Occurrence', 'AR Completeness', and 'Presentation \& Disclosure' have 
been met while 'Accounts. Rec.' is not fairly stated, then this leads us to conclude that the objective 'AR Accuracy \& Valuation' is not met.

--- Table 1 here ---

--- Figure 5 here ---

Table 1 represents the effects of the evidence, 'Third Party Utilization Reviewed', at 'Accounts Rec.' on all the variables in the network. The above evidence has its maximum impact on 'Accounts Rec.' because that is where it is directly connected (See also, Figure 5). For example, compare the overall support for 'Accounts Rec.' in row 1 in Table 1 with rows 2-5, 6-11, and 12-15 for different levels of support from the evidence. Also, notice that the impact of the evidence on various audit objectives at the account level is significantly reduced compared to the impact on the main objective, 'Accounts Rec.' The impact reduces further as we move away from the main objective towards the next level of variables (e.g., the variables at the transaction, and the sub-transaction levels, see Table 1). It is important to point out here that without other evidence in the network, the impact of this evidence will be the same at all levels of the network for a positive support. However, because of the impacts of all other items of evidence on the variables, the overall impact of this evidence on each variable becomes less prominent. Similar effects are observed for the negative support of the evidence (see Figure 6).

\section{--- Figure 6 here ---}

The above findings have practical implications on how the auditor collects further items of evidence. For example, suppose the auditor planned the audit with a 0.4 level of support from 'Third Party Utilization Reviewed' but after actually performing the procedure found out that the level of support is only 0.1. This change has caused the overall level of support for 'Accounts Rec.' to reduce from 0.957 to 0.935 (see columns 2 and 5 in Table 1). In order to increase 0.935 back to 0.95 level, the auditor has to change his or her plan. This will involve both the consideration of the cost in obtaining the evidence (or a set of evidence) and the desired level of support from each item of evidence. Auditor's Assistant can provide the help to the auditor in choosing a particular set of items of evidence (procedures) from several sets of possible procedures that would give the desired level of assurance. 
Srivastava, Rajendra. (1996) An Expert System Approach to Audit Planning and Evaluation in the Belief-Function Framework. International Journal of Intelligent Systems in Accounting, Finance and Management, 5 (3), 165-183. Publisher's Official Version: <http://onlinelibrary.wiley.com/journal/10.1002/\%28ISSN\%291099-1174>. Open Access Version: <http://kuscholarworks.ku.edu>.

Of course, the auditor's decision about choosing a particular set of procedures will be based on the lowest cost of performing the procedures.

When an item of evidence pertains to a sub-objective or a sub-sub-objective then the level of strength that propagates in the network depends on the direction. A positive item of evidence, say, at a sub-objective will propagate in its full strength to its sub-sub-objectives, as discussed earlier. However, the effect of the same evidence on the main objective will be affected by the type and strength of support on the other sub-objectives. For example, the evidence 'Subroutine 3' which provides a direct support of 0.334 to 'AR Accuracy \& Valuation' that it is true will provide an indirect support of the same amount to the following variables: 'Cash Receipts Accuracy \& Valuation', 'Revenue Accuracy \& Valuation', Prospective Payors, and 'Charge Payors'. However, the amount propagated to 'Accounts Rec.' will depend on the nature and strength of evidence at the other sub-objectives. If all other subobjectives had no evidence in favor of or against themselves then there will be no support for 'Accounts Rec.' from this evidence. However, if each of the other sub-objectives had, say, 0.8 degree of support for itself then $0.171(=0.344 \times 0.8 \times 0.8 \times 0.80)$ will propagate, in the current example, to 'Accounts Rec.' as a combined level of support from all the sub-objectives.

However, if the evidence pertaining to a sub-objective or a sub-sub-objective is negative, then the situation is different. The level of negative support will propagate in its full strength towards the main objective. This again makes intuitive sense. For example, if 'Subroutine 3' had a negative support of, say, 0.4 to 'AR Accuracy \& Valuation', the level of support from this evidence propagated to the main objective, 'Accounts Rec.' will also be negative with a strength of 0.4 irrespective of the kinds of evidence available at the other sub-objectives. The reason for this is that if one sub-objective is not met then the main objective is not met irrespective of whether any of the other sub-objectives are met or not met. For example, if 'AR Accuracy \& Valuation' is not met then we know that 'Accounts Rec.' is not fairly stated irrespective of whether the other audit objectives have been met.

--- Table 2 here ---

Table 2 represents the effects of the evidence 'Medical Records Licensure Required' at 'Revenue Existence and Occurrence' on various variables in the network. The changes in the overall support at 
Srivastava, Rajendra. (1996) An Expert System Approach to Audit Planning and Evaluation in the Belief-Function Framework. International Journal of Intelligent Systems in Accounting, Finance and Management, 5 (3), 165-183. Publisher's Official Version: <http://onlinelibrary.wiley.com/journal/10.1002/\%28ISSN\%291099-1174>. Open Access Version: <http://kuscholarworks.ku.edu>.

'Accounts Rec.' due to the changes in the strength of the above evidence are not as prominent in the case of a positive support as in the case of a negative support. This result is in accordance with what we discussed conceptually in the previous paragraph (Compare the numbers in row 1 in Table 2). Also, it is evident from rows 2, 6, 7, 12 and 14 that the impact of the evidence is limited to the neighborhood of 'Revenue Existence \& Occurrence' variable. This impact is again more prominent in the case of a negative support than it is in the case of a positive support. This result will have a similar kind of implication on the audit plan as we discussed earlier. The auditor will look at the neighboring variables and plan how to increase the support or propose an adjusting entry and modify the level of support for 'Revenue Existence \& Occurrence' objective. Auditor's Assistant can provide such an analysis to plan the audit for a desired level of overall support.

One implication of the 'and' relationship among the variables in the network is that the sub-, and sub-sub-objectives have very high level of positive overall support while the main objective, 'Accounts Rec.', does not have as high level of support (see Figure 1). The reason being that a positive item of evidence at the main objective level impacts all other objectives in the network at the same level. While a positive item of evidence at the sub- or sub-sub- objective level has a reduced effect when it is considered at the main objective level. Although we have been using the 'and' relationship, both in practice and in research, to represent the relationships (1) among the accounts and their audit objectives, and (2) among the balance sheet accounts such as accounts receivable and the corresponding transaction streams such as sales and cash receipts, we believe that 'and' does not really represent the relationship. Further research is needed to determine what kind of relationship holds between the variables in the evidential network.

\section{Effects of Variations in the Strength of Evidence on the Overall Belief}

Here we want to analyze the sensitivity of the overall belief at each variable in the network on the variability of input strength or belief obtained from each item of evidence. This issue is important for practical reasons. Since we require numerical inputs for the strength of evidence, how does one control for differences in estimates of the strength of evidence among auditors? One auditor may estimate, say, for a strong piece of evidence, a value 0.95 , whereas another auditor may estimate for the same piece 
of evidence, a value 0.90 . How will such a variation affect the overall belief? Our analysis provides an interesting insight to this problem.

\section{--- Table 3 here ---}

Table 3 provides a set of overall beliefs for each variable in Figure 1. The middle (fourth) column represents the overall belief for the set of input beliefs as estimated by one of the authors with a substantial experience in the health care industry. The next three columns represent the overall beliefs with an increase of 10,20, and 30 percent, respectively, in the input strengths for all the evidence in the network. By comparing column 4 with the other columns, we find that when all the evidence in the network are aggregated, the overall belief for each variable is almost unaffected by a change of $\pm 10 \%$ in all the input beliefs. The maximum impact is at the main variable, 'Accounts Rec.' and that too is not significant. For a change of $+10 \%$ in all the strengths, a change of merely $2.2 \%$ is observed for the overall belief that 'Accounts Rec.' is fairly stated. A change of - $10 \%$ in the input beliefs changes the overall belief that 'Accounts Rec.' is fairly stated by $-3.4 \%$. The corresponding changes in the overall beliefs for the other variables are even much smaller.

However, for a large variation in the input beliefs, we obtain a significantly large change in the overall belief, especially, at the account level. Columns 2, 3, 6, and 7 in Table 3 represents these results. A thirty percent decrease in all the input strengths yields a $15 \%$ decrease in the overall belief at 'Accounts Rec.'. A much smaller impact is observed at the audit objective level of the account. The decrease varies from $2.9 \%$ to $7.5 \%$. A variable with a smaller initial overall belief has a relatively larger decrease (see Table 3). These results have practical implications in the sense that a 5\% to $10 \%$ variation in the input strength may not effect the overall belief provided we have considered the interdependencies among the evidence and interrelationships among the audit objectives and the accounts. Auditor's Assistant provides a tool to fully incorporate the interdependencies and interrelationships. 


\section{SUMMARY AND CONCLUSION}

We have described a method to represent strength of evidence in terms of belief functions using $\mathrm{m}$-values (the basic probability assignment function). These values are used as inputs in Auditor's Assistant for aggregating evidence. The use of Auditor's Assistant is demonstrated for constructing evidential networks for audit decisions. Also, we have demonstrated the use of Auditor's Assistant on the audit of accounts receivable balance of a health care unit. The audit program was taken from a Big Six audit firm. Moreover, we have performed sensitivity analyses to determine the impact of the strength of evidence as a function of location in the network, and to investigate the effect of variability in the input strengths on the overall belief on each variable in the network. We have also discussed the implications on the audit process our results.

It is quite encouraging to know that Auditor's Assistant takes only about 6.5 minutes to aggregate all the evidence in Figure 3 on a Macintosh IIci with System 7.0 and eight megabyte memory. This seems like a reasonable time if one wants to perform a sensitivity analysis and determine what procedures or items of evidence are more important. Auditor's Assistant can be used to develop an interactive audit risk model for planning and evaluation of an audit. However, to use Auditor's Assistant effectively, further research needs to be done in several areas, including: (1) What is the most commonly accepted evidential network for the audit of a given account? (2) What should be the upper limit of assurance from certain audit procedures? (3) What is the relationship between a given account and its audit objectives for the evidential network - is it an 'and' relationship or some other relationship? (4) What type of relationship does exist between a balance sheet account and the corresponding accounts in the transaction streams? (4) What is the level of support one would obtain from statistical evidence?

The present study contains several limitations. First, the network used in the study is just one auditor's understanding of the evidential structure and thus lacks generalizability. Second, input numbers for the strength of evidence are estimates of one expert. This may change with a change of expert. The most fundamental question that remains unanswered is that whether the auditor makes judgments of the strength of evidence in terms of belief functions or something else. Regarding sensitivity analysis, we 
Srivastava, Rajendra. (1996) An Expert System Approach to Audit Planning and Evaluation in the Belief-Function Framework. International Journal of Intelligent Systems in Accounting, Finance and Management, 5 (3), 165-183. Publisher's Official Version: <http://onlinelibrary.wiley.com/journal/10.1002/\%28ISSN\%291099-1174>. Open Access Version: <http://kuscholarworks.ku.edu>.

think we should investigate the impact of the evidential structure, network versus a tree, on the overall belief. 


\section{APPENDIX}

\section{AUDITOR'S ASSISTANT: AN EXPERT SYSTEM SHELL}

Auditor's Assistant has been developed in Pascal in a Macintosh environment. The system uses the theoretical work on propagating beliefs in networks using local computations (see, e.g., Kong 1986, Mellouli 1987, Shenoy and Shafer 1986, 1990, and Srivastava 1995). The knowledge is represented by the evidential network. The expert knowledge is acquired by letting the user draw the pertinent evidential network in the situation using the graphical user-interface in the system. Hsia and Shenoy (1989) have described in detail the internal architecture of the system which takes the evidential network drawn graphically by the user and converts it internally into a "Markov tree $7 "$. The system uses this Markov tree to propagate belief functions in the network (See Srivastava 1995b for details on how to manually convert an evidential network into a Markov tree and then propagate beliefs).

\section{Knowledge Acquisition: Construction of The Evidential Network}

A network consists of variables and items of evidence bearing on the variables; variables being various audit objectives, accounts, and the financial statements. Here, we illustrate the process of constructing an evidential network using accounts receivable (AR) with only two audit objectives, 'Existence' and 'Valuation', as an example.

Panel (a) of Figure A1 appears on the screen as the system starts. A set of objects appears on the left side of the window for constructing a network. The oval shaped object with 'VA' creates variable nodes. The rectangular box with 'EV' creates evidential nodes. The hexagonal object with 'RE' creates relational nodes to relate various variables. The user can define the relationship as appropriate in the situation. The circle with ' $\&$ ' creates an 'and' relationship between a main objective and its subobjectives.

\section{(a) Construction of Variable Nodes and Relational Nodes}

Panel (a) in Figure A1 represents the first step in constructing a variable node. Here, the user highlights the object with 'VA' and places the cursor (represented by +) where the node is to be displayed in the network. Next, a window as shown in Panel (b) of Figure 1 appears. The user names 
Srivastava, Rajendra. (1996) An Expert System Approach to Audit Planning and Evaluation in the Belief-Function Framework. International Journal of Intelligent Systems in Accounting, Finance and Management, 5 (3), 165-183. Publisher's Official Version: <http://onlinelibrary.wiley.com/journal/10.1002/\%28ISSN\%291099-1174>. Open Access Version: <http://kuscholarworks.ku.edu>.

the variable and types the description about the variable. The system by default chooses two values, 'YES' and 'NO', of a variable, but the user has option to change it to have more than two values. After making all the entries on this panel the user selects 'OK' and Panel (c) of Figure 1 appears. Let us repeat the above procedures to create two more variables named 'AR Existence' and 'AR Valuation'.

\section{-- Figures A1 here --}

Assume the user decides that the two nodes 'AR Existence' and 'AR Valuation' are related to 'AR' through an 'and' node. This relationship means that accounts receivable (AR) is fairly stated if and only if the two objectives have been met. Such a relationship is established by first highlighting 'AR Existence' and 'AR Valuation' nodes and then highlighting the circle with '\&' on the left and placing the cursor on 'AR' node, as depicted in Panel (d) of Figure A1. Panel (e) of Figure A1 appears. We have constructed an 'and' relationship between 'AR' and its' two objectives.

To construct a relationship between variables that is not an 'and' relationship, one needs to highlight all the variables that are to be related and highlight the hexagonal object with 'RE' and place the cursor where the relational node is to be displayed in the network (see Panel (a) of Figure A2). A window appears for naming and describing the node. Once the name and description are typed, as shown in Panel (b), and the user has selected 'OK', the original screen returns with a relational node. In order to define the relationship, the user must select "Node-Input belief" from the menu. A new window as shown in Panel (c) appears. This window allows the user to either define a new relationship or modify or delete a relationship. In the present case, we select 'new' in Panel (c) which results into Panel (d). This panel provides a list of all possible set of values of the variables. The user must specify the relationship by providing the basic probability assignment function (or m-values) over the possible set of values that are permitted by the relationship. This is achieved by highlighting the set of values that are relevant for the relationship and assigning a value for the corresponding $\mathrm{m}$-value.

Let us construct an 'OR' relationship between the variables A, and B and C. This relationship implies that Variable $\mathrm{A}$ is true when either $\mathrm{B}$ or $\mathrm{C}$ is true or when both $\mathrm{B}$ and $\mathrm{C}$ are true but $\mathrm{A}$ is not true when both $\mathrm{B}$ and $\mathrm{C}$ are not true. This relationship allows only the following set of values $\{(\mathrm{YES}, \mathrm{YES}, \mathrm{YES}),(\mathrm{YES}, \mathrm{YES}, \mathrm{NO}),(\mathrm{YES}, \mathrm{NO}, \mathrm{YES}),(\mathrm{NO}, \mathrm{NO}, \mathrm{NO})\}$ for the three variables where 
the first value represents $\mathrm{A}$, the second one $\mathrm{B}$, and the third one $\mathrm{C}$. In the belief-function framework this relationship is represented by assigning a value of 1.0 to the $\mathrm{m}$-value for the above set of values, i.e., $\mathrm{m}(\{(\mathrm{YES}, \mathrm{YES}, \mathrm{YES}),(\mathrm{YES}, \mathrm{YES}, \mathrm{NO}),(\mathrm{YES}, \mathrm{NO}, \mathrm{YES}),(\mathrm{NO}, \mathrm{NO}, \mathrm{NO})\})=1$. This assignment is made by highlighting the set of values as shown in Panels (d) and (e). Panel (f) represents the desired relationship. The user can create a relationship that is not necessarily a categorical relationship by selecting the possible sets of values and assigning appropriate $\mathrm{m}$-values.

\section{-- Figure A2 here --}

\section{(b) Construction of Evidential Nodes}

An evidence node is always related to one or more than one variable node. Thus, in creating an evidence node, the user has to first highlight the variable node or nodes and then highlight the rectangular object with 'EV' on the left and place the cursor where the node is to be displayed in the network. The newly created evidence node will not have input beliefs and thus will appear with a dotted outline. In order to input the strength of evidence, the user must select 'Node-Input belief' from the menu, choose 'new' from the next window, enter the desired level of m-values to the desired set of value(s) of the variable(s). The evidence node appears in solid lines once the judgment about the strength is input. 


\section{FOOTNOTES}

1. Auditor's Assistant (AA) was developed by Shafer, Shenoy and Srivastava (1988) with the support from the Peat Marwick Foundation.

2. A tree type structure where one item of evidence supports one account or one audit objective.

3. There are several articles that deal with the basic concepts of belief functions (see, e.g., Shafer and Srivastava 1990; Srivastava and Shafer 1992, Srivastava 1993, 1995a, 1995b). In particular, see Srivastava (1993) that deals with the basics of belief functions. Of course, Shafer (1976) provides the most comprehensive coverage of belief functions.

4. The basic probability assignment function or the $m$-function assigns uncertainty to a subset of elements of a frame. A frame is an exhaustive and mutually exclusive set of possible answers to a question . In the case of a yes-no question, the frame has only two elements: $\{$ yes,no\}. But, in general, a frame may be a very large set, for its question may have many possible answers. The difference between $\mathrm{m}$-values and probabilities is that probabilities are assigned to individual elements of a frame, whereas $m$-values are assigned to a subset of elements of the frame. The sum of all the m-values for all the subsets of the frame is 1 (See Srivastava and Shafer, 1992 for details).

5. If the focal elements over which m-values are defined can be arranged in such a way that the largest element contains the next largest element and the next one contains the next largest element and so on then the focal elements are nested. For example, suppose that variable Y has four values: $\left\{\mathrm{y}_{1}\right.$, $\left.y_{2}, y_{3}, y_{4}\right\}$ and we have non-zero $m$-values at the following set of elements: $\theta_{1}=\left\{y_{1}\right\}, \theta_{2}=\left\{y_{1}\right.$, $\left.\mathrm{y}_{2}\right\}, \theta_{3}=\left\{\mathrm{y}_{1}, \mathrm{y}_{2}, \mathrm{y}_{3}\right\}, \theta_{4}=\left\{\mathrm{y}_{1}, \mathrm{y}_{2}, \mathrm{y}_{3}, \mathrm{y}_{4}\right\}$. These elements are nested because they satisfy the condition: $\theta_{4} \supset \theta_{3} \supset \theta_{2} \supset \theta_{1}$. If the arguments of $\mathrm{m}$-values, i.e., the focal elements of $\mathrm{m}$-values are nested then the resulting $\mathrm{m}$-values are called nested $\mathrm{m}$-values and the corresponding belief functions are called nested belief functions (Shafer (1976) calls such belief functions as consonant belief functions).

Assume that an item of evidence provides 0.9 degree of support to a variable $\mathrm{E}$ that it is met (e) and 0.8 degree of support to A that it is met (a), i.e., $\operatorname{Bel}(\mathrm{e})=0.9$, and $\operatorname{Bel}(\mathrm{a})=0.8$. Let us also assume that there is no support for the negation of the variables, i.e., $\operatorname{Bel}(\sim e)=0$, and $\operatorname{Bel}(\sim a)=0$. The non-zero $\mathrm{m}$-values that represent the above beliefs can be written in terms of nested $\mathrm{m}$-values as:

$\mathrm{m}(\{$ ea $\})=0.8, \mathrm{~m}(\{$ ea, e a $\})=0.1, \mathrm{~m}(\{$ ea, e a,$\sim$ ea,$\sim \mathrm{e} \sim \mathrm{a}\})=0.1$.

If we marginalize the above $m$-values for each variable then we get the desired beliefs. See Srivastava and Shafer (1992) for marginalization of belief functions.

6. One of the authors has 11 years of experience in auditing the health care units and was involved in developing the audit manual for the health care units for one of the Big Six audit firms.

7. A Markov tree is a topological tree whose nodes are subsets of variables with the property that if a variable belongs to two distinct nodes, then every node lying on the path between these two nodes contain the variable (Shenoy 1991). 


\section{REFERENCES}

Akresh, A.D., J.K. Loebbecke, and W. R. Scott. 1988. Audit approaches and techniques. In Research Opportunities in Auditing: The Second Decade, edited by A. R. Abdel-khalik and Ira Solomon. Sarasota, FL: AAA, pp. 13-55.

American Institute of Certified Public Accountants. 1983. Statement on Auditing Standards, No, 47: Audit Risk and Materiality in Conducting an Audit. New York: AICPA.

Arens, A.A., and J.K. Loebbecke. 1994. AUDITING: An Integrated Approach. Prentice Hall, Inc., New Jersey.

Boritz, J.E. and .A.K.P. Wensley. 1990. Structuring the Assessment of Audit Evidence: An Expert System Approach. Auditing: A Journal of Practice and Theory (Supplement).

Boritz, J. E., and A. K. P. Wensley. 1992. CAPEX: A Knowledge-Based Expert System for Substantive Audit Planning. Markus Werner Publishing, Princeton, NJ.

Brown C.E., and D.E. O’Leary. 1993. Introduction to Artificial Intelligence and Expert Systems. Working Paper, School of Business, Oregon State University.

Chandler, J.S. 1985. Expert Systems in Auditing: The State of the Art. The Auditor's Report, Vol. 8, N0.3 (Summer), pp. 1-4.

Dubois, D. and H. Prade. 1986. The Principles of Minimum Specificity as a Basis for Evidential Reasoning. Lecture Notes in Computer Science. edited by G. Goos and J. Hartmanis. SpringerVerlag.

. and 1987. The Principles of Minimum Specificity as a Basis for Evidential Reasoning. in Uncertainty in Knowledge-Based Systems (Bouchon B., Yager R. R. eds.), SpringerVerlag, LNCS, Vol. no. 286, pp. 74-84.

and 1992. Evidence, Knowledge, and Belief Functions. Internal Journal of Approximate Reasoning, Vol. 6, pp. 295-319. . and 1994. Focusing versus Updating in Belief Function Theory. Advances in the Dempster-Shafer Theory of Evidence, (Yager, R.R., Kacprzyk, J, and Fedrizzi, M. eds.), Wiley, pp. 71-95.

Dutta, S.K., and R.P. Srivastava. 1993. Aggregation of Evidence in Auditing: A Likelihood Perspective. Auditing: A Journal of Practice and Theory, (Supplement), pp. 137-160.

Graham, L.E. 1985. Audit risk - Part I. The CPA Journal (August), pp. 12-21.

Gillett, P. 1993. Automatic Dynamic Audit Programme Tailoring: An Expert Systems Approach. Auditing: A Journal of Practice and Theory (Supplement), pp. 173-89. 
Srivastava, Rajendra. (1996) An Expert System Approach to Audit Planning and Evaluation in the Belief-Function Framework. International Journal of Intelligent Systems in Accounting, Finance and Management, 5 (3), 165-183. Publisher's Official Version: <http://onlinelibrary.wiley.com/journal/10.1002/\%28ISSN\%291099-1174>. Open Access Version: <http://kuscholarworks.ku.edu>.

Hansen, J.V., and W.F. Messier. 1982. Expert Systems for Decision Support in EDP Auditing. International Journal of Computer and Information Sciences, Vol. 11, No. 5 , pp. 357-379. . and 1986a. A Preliminary Investigation of EDP-XPERT. Auditing: A Journal of Practice and Theory, Vol. 6, No. 1, pp. 109-123. and . 1986b. A Knowledge Based Expert System for Auditing Advanced Computer Systems. European Journal Operations Research (September), pp. 371-379.

Hsia, Y-T, and P. Shenoy. 1989. An Evidential Language for Expert Systems. Proceedings of the Fourth International Symposium on Methodologies for Intelligent Systems. Charlotte, North Carolina, pp. 9-16.

Kong, A. 1986. Multivariate Belief Functions and Graphical Models. Doctoral Dissertation, Department of Statistics, Harvard University.

Leslie, D.A., and Stephen J. Aldersley, Donald J. Cockburn, and Carolyn J. Reiter. 1986. An Assertion Based Approach to Auditing. Proceedings of the 1986 Touche Ross/University of Kansas Symposium on Auditing Problems (May), pp. 31-67.

Mellouli, K. 1987. On the Propagation of Beliefs in Networks Using the Dempster-Shafer Theory of Evidence. Doctoral Dissertation, School of Business, University of Kansas.

Messier, W.F., and J.V. Hansen. 198?. A Case Study and Field Evaluation of EDP-XPERT. International Journal of Intelligent Systems in Accounting, Finance and Management, Vol.1, No. 1, pp. 173-186.

Saffiotti, A. and E. Umkehrer. 1991. Pulcinella: A General Tool for Propagating Uncertainty in Valuation Networks. Proceedings of the Seventh National Conference on Artificial Intelligence. University of California at Los Angeles, pp. 323-331.

Shafer, G. 1976. A Mathematical Theory of Evidence. Princeton University Press.

., P.P. Shenoy, and R.P. Srivastava. 1988. Auditor's Assistant: A Knowledge Engineering Tool For Audit Decisions. Proceedings of the 1988 Touche Ross/University of Kansas Symposium of Auditing Problems, pp. 61-85.

, and R.P. Srivastava. 1990. The Bayesian and Belief-Function Formalisms-A General Perspective For Auditing. Auditing: A Journal of Practice and Theory, (Supplement), pp. 110148.

Shenoy, P.P. 1991. Valuation-Based System for Discrete Optimization. Uncertainty in Artificial Intelligence, Vol. 6, North-Holland, Amsterdam, edited by P. P. Bonissone, M. Henrion, L. N. Kanal, and J. Lemmer, pp. 385-400. ., and G. Shafer. 1986. Propagating Belief Functions using Local Computations. IEEE Expert, 1 (3), pp. 43-52. 
, and 1990. Axioms for Probability and Belief-Function Propagation.

Uncertainty in Artificial Intelligence, 4 (R. D. Shachter, T. S. Levitt, J. F. Lemmer, and L. N. Kanal, Eds.), North-Holland, pp. 169-198.

Srivastava, R.P. 1993. Belief Functions and Audit Decisions. Auditors Report, Vol. 17, No. 1 (Fall), pp. 8-12.

1995a. A General Scheme for Aggregating Evidence in Auditing: Propagation of Beliefs in Networks. Artificial Intelligence in Accounting and Auditing, Vol. 2. Miklos A. Vasarhelyi, editor, Markus Wiener Publishers.

. 1995b. The Belief-Function Approach to Aggregating Audit Evidence. International Journal of Intelligent Systems, pp. 329-356.

., and K. O. Cogger. 1996. Algorithm for Converting Beliefs on Individual Variables from a Single Source of Evidence to m-values on the Joint Space. School of Business Working Paper, University of Kansas.

. and G. Shafer. 1994. Integrating Statistical and Non-Statistical Audit Evidence Using Belief Functions: A Case of Variable Sampling. International Journal of Intelligent Systems, pp. 519-539. ., and . Belief-Function Formulas for Audit Risk. The Accounting Review, (April) pp. 249-283.

Vasarhelyi, M.A. 1990. Artificial Intelligence in Accounting and Auditing: Using Expert Systems, Vol. I. Markus Werner Publishers.

Vasarhelyi, M.A., and B.N. Srinidhi. 1993. Artificial Intelligence, Vol. II. Markus Werner Publishers.

. 1995. Artificial Intelligence, Vol. III. Markus Werner Publishers.

Zarley, D., Y-T. Hsia, and G. Shafer. 1988. Evidential Reasoning Using DELIEF. Proceedings of the Seventh National Conference on Artificial Intelligence. St. Paul, MN, Vol. 1, Cambridge, MA: AAAI Press, pp. 205-209. 
Srivastava, Rajendra. (1996) An Expert System Approach to Audit Planning and Evaluation in the Belief-Function Framework

International Journal of Intelligent Systems in Accounting, Finance and Management, 5 (3), 165-183. Publisher's Official Version:

<http://onlinelibrary.wiley.com/journal/10.1002/\%28ISSN\%291099-1174>. Open Access Version: <http://kuscholarworks.ku.edu>.

Table 1

Effect of an Item of Evidence at the Main Objective, 'Accounts Rec.', on Various Objectives in the Network.

\begin{tabular}{|c|c|c|c|c|c|c|c|c|c|c|}
\hline Objectives & $\begin{array}{r}(+;-) \\
0.5 ; 0\end{array}$ & $\begin{array}{r}(+;-) \\
0.4 ; 0\end{array}$ & $\begin{array}{c}\text { Level o } \\
(+;-) \\
0.3 ; 0\end{array}$ & $\begin{array}{r}\text { Ipport }^{*} \\
(+;-) \\
0.2 ; 0 \\
\end{array}$ & $\begin{array}{r}\text { 'Third } \\
(+;-) \\
0.1 ; 0\end{array}$ & $\begin{array}{l}\text { Utilizatior } \\
(+;-) \\
000 ; .100\end{array}$ & $\begin{array}{l}\text { eviewed' } \\
(+;-) \\
000 ; .200 \\
\end{array}$ & $\begin{array}{l}(+;-) \\
000 ; .300\end{array}$ & $\begin{array}{l}(+;-) \\
000 ; .400\end{array}$ & $\begin{array}{l}(+;-) \\
000 ; .500\end{array}$ \\
\hline Accounts Rec. & $.964 ; 0$ & $.957 ; 0$ & $.949 ; 0$ & $.942 ; 0$ & $.935 ; 0$ & $.920 ; .008$ & $.911 ; .018$ & $.900 ; .030$ & $.885 ; .046$ & $.865 ; .067$ \\
\hline $\begin{array}{l}\text { At the Account Level } \\
\text { AR Existence \& Occurrence } \\
\text { AR Completeness } \\
\text { AR Accuracy \& Valuation } \\
\text { Presentation \& Disclosure }\end{array}$ & $\begin{array}{l}.991 ; 0 \\
.986 ; 0 \\
.998 ; 0 \\
.984 ; 0\end{array}$ & $\begin{array}{l}.989 ; 0 \\
.983 ; 0 \\
.997 ; 0 \\
.981 ; 0\end{array}$ & $\begin{array}{l}.987 ; 0 \\
.980 ; 0 \\
.997 ; 0 \\
.978 ; 0\end{array}$ & $\begin{array}{l}.985 ; 0 \\
.977 ; 0 \\
.996 ; 0 \\
.975 ; 0\end{array}$ & $\begin{array}{l}.983 ; 0 \\
.974 ; 0 \\
.996 ; 0 \\
.971 ; 0\end{array}$ & $\begin{array}{l}.980 ; .001 \\
.968 ; .002 \\
.995 ; \quad 0 \\
.965 ; .003\end{array}$ & $\begin{array}{l}.977 ; .003 \\
.965 ; .005 \\
.994 ; .001 \\
.961 ; .006\end{array}$ & $\begin{array}{l}.974 ; .005 \\
.960 ; .009 \\
.993 ; .001 \\
.956 ; .011\end{array}$ & $\begin{array}{l}.970 ; .008 \\
.954 ; .014 \\
.993 ; .002 \\
.949 ; .017\end{array}$ & $\begin{array}{l}. .965 ; .012 \\
.947 ; .020 \\
.991 ; .002 \\
.941 ; .024\end{array}$ \\
\hline $\begin{array}{l}\text { At the Transaction Level } \\
\text { Revenue Existence \& Occurrence } \\
\text { Cash Receipts Completeness } \\
\text { Revenue Completeness } \\
\text { Cash Receipts Existence } \\
\text { Cash Receipts Accuracy \& Val. } \\
\text { Revenue Accuracy \& Valuation }\end{array}$ & $\begin{array}{l}.997 ; 0 \\
.994 ; 0 \\
.987 ; 0 \\
.999 ; 0 \\
.998 ; 0 \\
.999 ; 0\end{array}$ & $\begin{array}{l}.996 ; 0 \\
.992 ; 0 \\
.984 ; 0 \\
.998 ; 0 \\
.997 ; 0 \\
.999 ; 0\end{array}$ & $\begin{array}{l}.995 ; 0 \\
.991 ; 0 \\
.981 ; 0 \\
.998 ; 0 \\
.997 ; 0 \\
.999 ; 0\end{array}$ & $\begin{array}{l}.995 ; 0 \\
.990 ; 0 \\
.979 ; 0 \\
.998 ; 0 \\
.997 ; 0 \\
.999 ; 0\end{array}$ & $\begin{array}{l}.994 ; 0 \\
.989 ; 0 \\
.976 ; 0 \\
.997 ; 0 \\
.996 ; 0 \\
.999 ; 0\end{array}$ & $\begin{array}{lr}.993 ; & 0 \\
.986 ; .001 \\
.971 ; .002 \\
.997 ; \quad 0 \\
.995 ; \quad 0 \\
.999 ; \quad 0\end{array}$ & $\begin{array}{l}.992 ; .001 \\
.985 ; .002 \\
.967 ; .005 \\
.997 ; \quad 0 \\
.995 ; .001 \\
.999 ; \quad 0\end{array}$ & $\begin{array}{l}.991, .002 \\
.983 ; .003 \\
.963 ; .008 \\
.996 ; \quad 0 \\
.994 ; .001 \\
.999 ; \quad 0\end{array}$ & $\begin{array}{l}.990 ; .003 \\
.980 ; .005 \\
.957 ; .013 \\
.995 ; .001 \\
.993 ; .001 \\
.999 ; \quad 0\end{array}$ & $\begin{array}{l}.988 ; .004 \\
.976 ; .007 \\
.950 ; .018 \\
.995 ; .001 \\
.992 ; .002 \\
.999 ; \quad 0\end{array}$ \\
\hline $\begin{array}{l}\text { At the Sub-transaction Level } \\
\frac{\text { Revenue Existence \& Occurrence }}{\text { Charge Payors }} \\
\text { Prospective Payors }\end{array}$ & $\begin{array}{l}.997 ; 0 \\
.999 ; 0\end{array}$ & $\begin{array}{l}.996 ; 0 \\
.999 ; 0\end{array}$ & $\begin{array}{l}.995 ; 0 \\
.999 ; 0\end{array}$ & $\begin{array}{l}.995 ; 0 \\
.999 ; 0\end{array}$ & $\begin{array}{l}.994 ; 0 \\
.999 ; 0\end{array}$ & $\begin{array}{ll}.993 ; & 0 \\
.999 ; & 0\end{array}$ & $\begin{array}{l}.992 ; .001 \\
.999 ; \quad 0\end{array}$ & $\begin{array}{r}.991 ; .002 \\
.999, \quad 0\end{array}$ & $\begin{array}{l}.990 ; .003 \\
.999 ; \quad 0\end{array}$ & $\begin{array}{l}.988 ; .004 \\
.999 ; \quad 0\end{array}$ \\
\hline $\begin{array}{l}\text { Revenue Accuracy and Valuation } \\
\text { Prospective Payors } \\
\text { Charge payors }\end{array}$ & $\begin{array}{l}.999 ; 0 \\
.999 ; 0\end{array}$ & $\begin{array}{l}.999 ; 0 \\
.999 ; 0\end{array}$ & $\begin{array}{l}.999 ; 0 \\
.999 ; 0\end{array}$ & $\begin{array}{l}.999 ; 0 \\
.999 ; 0\end{array}$ & $\begin{array}{l}.999 ; 0 \\
.999 ; 0\end{array}$ & $\begin{array}{cc}.999 ; & 0 \\
.999 ; & 0\end{array}$ & $\begin{array}{ll}.999 ; & 0 \\
.999 ; & 0\end{array}$ & $\begin{array}{ll}.999 ; & 0 \\
.999 ; & 0\end{array}$ & $\begin{array}{ll}.999 ; & 0 \\
.999 ; & 0\end{array}$ & $\begin{array}{ll}.999 ; & 0 \\
.999 ; & 0\end{array}$ \\
\hline
\end{tabular}

* In each column, the first number represents the level of positive support, $\mathrm{m}(\mathrm{x})$, for the objective that it is met and the second number represents the level of negative support, $\mathrm{m}(\sim \mathrm{x})$, which implies that the objective is not met. 
Srivastava, Rajendra. (1996) An Expert System Approach to Audit Planning and Evaluation in the Belief-Function Framework.

International Journal of Intelligent Systems in Accounting, Finance and Management, 5 (3), 165-183. Publisher's Official Version:

<http://onlinelibrary.wiley.com/journal/10.1002/\%28ISSN\%291099-1174>. Open Access Version: <http://kuscholarworks.ku.edu>.

Table 2

Effect of an Item of Evidence at the Intermediate Level in the Network (e.g., at 'Revenue Existence \& Occurrence') on Various Objectives.

\begin{tabular}{|c|c|c|c|c|c|c|c|c|c|c|}
\hline Objectives & $\begin{array}{r}1 \\
(+;-) \\
0.6 ; 0\end{array}$ & $\begin{array}{c}\text { el of sup } \\
(+;-) \\
0.5 ; 0\end{array}$ & $\begin{array}{c}\mathrm{rt}^{*} \text { from } \\
(+;-) \\
0.4 ; 0\end{array}$ & $\begin{array}{r}\text { Uedical R } \\
(+;-) \\
0.3 ; 0\end{array}$ & $\begin{array}{r}\text { ords Lin } \\
(+;-) \\
0.2 ; 0 \\
\end{array}$ & $\begin{array}{l}\text { sure Required' } \\
(+;-) \\
0.1 ; 0\end{array}$ & $\begin{array}{l}(+;-) \\
000 ; .100\end{array}$ & $\begin{array}{c}(+;-) \\
000 ; .200\end{array}$ & $\begin{array}{l}(+;-) \\
000 ; .300\end{array}$ & $\begin{array}{l}(+;-) \\
000 ; .400\end{array}$ \\
\hline Accounts Rec. & $.957 ; 0$ & $.956 ; 0$ & $.955 ; 0$ & $.955 ; 0$ & $.954 ; 0$ & $.953 ; 0$ & $.952 ; .001$ & $.950 ; .002$ & $.949 ; .004$ & $.947 ; .006$ \\
\hline $\begin{array}{l}\text { At the Account Level } \\
\text { AR Existence \& Occurrence } \\
\text { AR Completeness } \\
\text { AR Accuracy \& Valuation } \\
\text { Presentation \& Disclosure }\end{array}$ & $\begin{array}{l}.989 ; 0 \\
.983 ; 0 \\
.997 ; 0 \\
.981 ; 0\end{array}$ & $\begin{array}{l}.988 ; 0 \\
.983 ; 0 \\
.997 ; 0 \\
.981 ; 0\end{array}$ & $\begin{array}{l}.987 ; 0 \\
.983 ; 0 \\
.997 ; 0 \\
.981 ; 0\end{array}$ & $\begin{array}{l}.986 ; 0 \\
.983 ; 0 \\
.997 ; 0 \\
.981 ; 0\end{array}$ & $\begin{array}{l}.985 ; 0 \\
.983 ; 0 \\
.997 ; 0 \\
.981 ; 0\end{array}$ & $\begin{array}{l}.984 ; 0 \\
.983 ; 0 \\
.997 ; 0 \\
.981 ; 0\end{array}$ & $\begin{array}{ll}.982 ; .001 \\
.983 ; & 0 \\
.997 ; & 0 \\
.981 ; & 0\end{array}$ & $\begin{array}{ll}.981 ; .002 \\
.982 ; & 0 \\
.997 ; & 0 \\
.981 ; & 0\end{array}$ & $\begin{array}{ll}.979 ; .004 \\
.982 ; & 0 \\
.997 ; & 0 \\
980 ; & 0\end{array}$ & $\begin{array}{l}.977 ; .006 \\
.982 ; \quad 0 \\
.997 ; \quad 0 \\
.980 ; \quad 0\end{array}$ \\
\hline $\begin{array}{l}\text { At the Transaction Level } \\
\text { Revenue Existence \& Occurrence } \\
\text { Cash Receipts Completeness } \\
\text { Revenue Completeness } \\
\text { Cash Receipts Existence } \\
\text { Cash Receipts Accuracy \& Val. } \\
\text { Revenue Accuracy \& Valuation }\end{array}$ & $\begin{array}{l}.996 ; 0 \\
.992 ; 0 \\
.984 ; 0 \\
.998 ; 0 \\
.997 ; 0 \\
.999 ; 0\end{array}$ & $\begin{array}{l}.995 ; 0 \\
.992 ; 0 \\
.984 ; 0 \\
.998 ; 0 \\
.997 ; 0 \\
.999 ; 0\end{array}$ & $\begin{array}{l}.994 ; 0 \\
.992 ; 0 \\
.984 ; 0 \\
.998 ; 0 \\
.997 ; 0 \\
.999 ; 0\end{array}$ & $\begin{array}{l}.993 ; 0 \\
.992 ; 0 \\
.984 ; 0 \\
.998 ; 0 \\
.997 ; 0 \\
.999 ; 0\end{array}$ & $\begin{array}{l}.992 ; 0 \\
.992 ; 0 \\
.984 ; 0 \\
.998 ; 0 \\
.997 ; 0 \\
.999 ; 0\end{array}$ & $\begin{array}{l}.991 ; 0 \\
.992 ; 0 \\
.984 ; 0 \\
.998 ; 0 \\
.997 ; 0 \\
.999 ; 0\end{array}$ & $\begin{array}{ll}.989 ; .001 \\
.992 ; & 0 \\
.984 ; & 0 \\
.998 ; & 0 \\
.997 ; & 0 \\
.999 ; & 0\end{array}$ & $\begin{array}{lr}.988 ; .002 \\
.992 ; & 0 \\
.984 ; & 0 \\
.998, & 0 \\
.997 ; & 0 \\
.999 ; & 0\end{array}$ & $\begin{array}{ll}.986 ; .004 \\
.992 ; & 0 \\
.983 ; & 0 \\
.998 ; & 0 \\
.997 ; & 0 \\
.999 ; & 0\end{array}$ & $\begin{array}{ll}.984 ; .006 \\
.992 ; & 0 \\
.983 ; & 0 \\
.998 ; & 0 \\
.997 ; & 0 \\
.999 ; & 0\end{array}$ \\
\hline $\begin{array}{l}\text { At the Sub-transaction Level } \\
\frac{\text { Revenue Existence \& Occurrence }}{\text { Charge Payors }} \\
\text { Prospective Payors } \\
\text { Revenue Accuracy and Valuation } \\
\text { Prospective Payors } \\
\text { Charge payors }\end{array}$ & $\begin{array}{l}.996 ; 0 \\
.999 ; 0 \\
.999 ; 0 \\
.999 ; 0\end{array}$ & $\begin{array}{l}.995 ; 0 \\
.999 ; 0\end{array}$ & $\begin{array}{l}.994 ; 0 \\
.999 ; 0\end{array}$ & $\begin{array}{l}.993 ; 0 \\
.999 ; 0\end{array}$ & $\begin{array}{l}.992 ; 0 \\
.999,0\end{array}$ & $\begin{array}{l}.991 ; 0 \\
.999 ; 0\end{array}$ & $\begin{array}{l}.989 ; .001 \\
.999 ; \quad 0\end{array}$ & $\begin{array}{l}.988 ; .002 \\
.999 ; \quad 0\end{array}$ & $\begin{array}{ll}.986 ; .004 \\
.999 ; & 0 \\
.999 ; & 0 \\
.999 ; & 0\end{array}$ & $\begin{array}{l}.984 ; .006 \\
.999 ; \quad 0\end{array}$ \\
\hline
\end{tabular}

* In each column, the first number represents the level of positive support, $\mathrm{m}(\mathrm{x})$, for the objective that it is met and the second number represents the level of negative support, $\mathrm{m}(\sim \mathrm{x})$, which implies that the objective is not met. 
Srivastava, Rajendra. (1996) An Expert System Approach to Audit Planning and Evaluation in the Belief-Function Framework.

International Journal of Intelligent Systems in Accounting, Finance and Management, 5 (3), 165-183. Publisher's Official Version:

<http://onlinelibrary.wiley.com/journal/10.1002/\%28ISSN\%291099-1174>. Open Access Version: <http://kuscholarworks.ku.edu>.

Table 3

The Overall Belief for Each Variable in the Network in Figure 3.*

\begin{tabular}{|c|c|c|c|c|c|c|c|c|}
\hline \multirow[b]{2}{*}{ Objectives } & \multicolumn{8}{|c|}{ Percentage Change in the strength of Evidence for all Items of Evidence } \\
\hline & $-30 \%$ & $-20 \%$ & $-10 \%$ & $0 \%$ & $+10 \%$ & & $+20 \%$ & $+30 \%$ \\
\hline Accounts Rec. & $0.813(-15.0)$ & $0.876(-8.5)$ & $0.924(-3.4)$ & 0.957 & 0.978 & $(2.2)$ & $0.992(3.7)$ & $0.997(4.18)$ \\
\hline \multicolumn{9}{|l|}{ At the Account Level } \\
\hline AR Existence \& Occurrence & $0.921(-6.9)$ & $0.955(-3.4)$ & $0.976(-1.3)$ & 0.989 & 0.996 & $(0.7)$ & $0.999(1.0)$ & $0.999(1.01)$ \\
\hline AR Completeness & $0.921(-6.3)$ & $0.951(-3.3)$ & $0.971(-1.2)$ & 0.983 & 0.990 & $(0.7)$ & $0.995(1.2)$ & $0.997(1.42)$ \\
\hline AR Accuracy \& Valuation & $0.968(-2.9)$ & $0.985(-1.2)$ & $0.993(-0.4)$ & 0.997 & 0.999 & $(0.2)$ & $0.999(0.2)$ & $0.999(0.20)$ \\
\hline Presentation \& Disclosure & $0.907(-7.5)$ & $0.941(-4.1)$ & $0.965(-1.6)$ & 0.981 & 0.991 & $(1.0)$ & $0.998(1.7)$ & $1(1.94)$ \\
\hline \multicolumn{9}{|l|}{ At the Transaction Level } \\
\hline Revenue Existence \& Occurrence & $0.967(-2.9)$ & $0.983(-1.3)$ & $0.991(-0.5)$ & 0.996 & 0.998 & $(0.2)$ & $0.999(0.3)$ & $0.999(0.30)$ \\
\hline Cash Receipts Completeness & $0.946(-4.6)$ & $0.969(-2.3)$ & $0.984(-0.8)$ & 0.992 & 0.997 & $(0.5)$ & $0.999(0.7)$ & $1(0.81)$ \\
\hline Revenue Completeness & $0.932(-5.3)$ & $0.957(-2.7)$ & $0.973(-1.1)$ & 0.984 & 0.991 & $(0.7)$ & $0.995(1.1)$ & $0.997(1.32)$ \\
\hline Cash Receipts Existence & $0.978(-2.0)$ & $0.989(-0.9)$ & $0.995(-0.3)$ & 0.998 & 0.999 & $(0.1)$ & $0.999(0.1)$ & $1(0.20)$ \\
\hline Cash Receipts Accuracy \& Val. & $0.975(-2.2)$ & $0.987(-1.0)$ & $0.994(-0.3)$ & 0.997 & 0.999 & $(0.2)$ & $0.999(0.2)$ & $0.999(0.20)$ \\
\hline Revenue Accuracy \& Valuation & $0.992(-0.7)$ & $0.997(-0.2)$ & $0.999(0.00)$ & 0.999 & 0.999 & $(0.0)$ & $0.999(0.0)$ & $0.999(0.00)$ \\
\hline \multicolumn{9}{|l|}{ At the Sub-transaction Level } \\
\hline \multicolumn{9}{|l|}{ Revenue Existence \& Occurrence } \\
\hline Charge Payors & $0.967(-2.9)$ & $0.983(-1.3)$ & $0.991(-0.5)$ & 0.996 & 0.998 & $(0.2)$ & $0.999(0.3)$ & $0.999(0.30)$ \\
\hline Prospective Payors & $0.991(-0.8)$ & $0.997(-0.2)$ & $0.999(0.00)$ & 0.999 & 0.999 & $(0.0)$ & $0.999(0.0)$ & $1(0.10)$ \\
\hline \multicolumn{9}{|l|}{ Revenue Accuracy and Valuation } \\
\hline Prospective Payors & $0.998(-0.1)$ & $0.999(-0.0)$ & $0.999(0.00)$ & 0.999 & 0.999 & $(0.0)$ & $1(0.1)$ & $1(0.10)$ \\
\hline Charge payors & $0.993(-0.6)$ & $0.997(-0.2)$ & $0.999(0.00)$ & 0.999 & 0.999 & $(0.0)$ & $0.999(0.0)$ & $0.999(0.00)$ \\
\hline
\end{tabular}

*Auditor's Assistant is used to combine all the evidence.

\#The number in a parenthesis represents the percentage change in the overall belief at the corresponding objective. 
Srivastava, Rajendra. (1996) An Expert System Approach to Audit Planning and Evaluation in the Belief-Function Framework.

International Journal of Intelligent Systems in Accounting, Finance and Management, 5 (3), 165-183. Publisher's Official Version:

<http://onlinelibrary.wiley.com/journal/10.1002/\%28ISSN\%291099-1174>. Open Access Version: <http://kuscholarworks.ku.edu>.

\section{Figure 1}

Evidential Network for Accounts Receivable for a Health Care Unit. (Each evidence box contains the specific procedure(s) along with the abbreviated symbols in parentheses as listed in the actual program, available from the authors on request. IF stands for inherent factors. Subroutines 1-7 are given in Figure 2-4.)

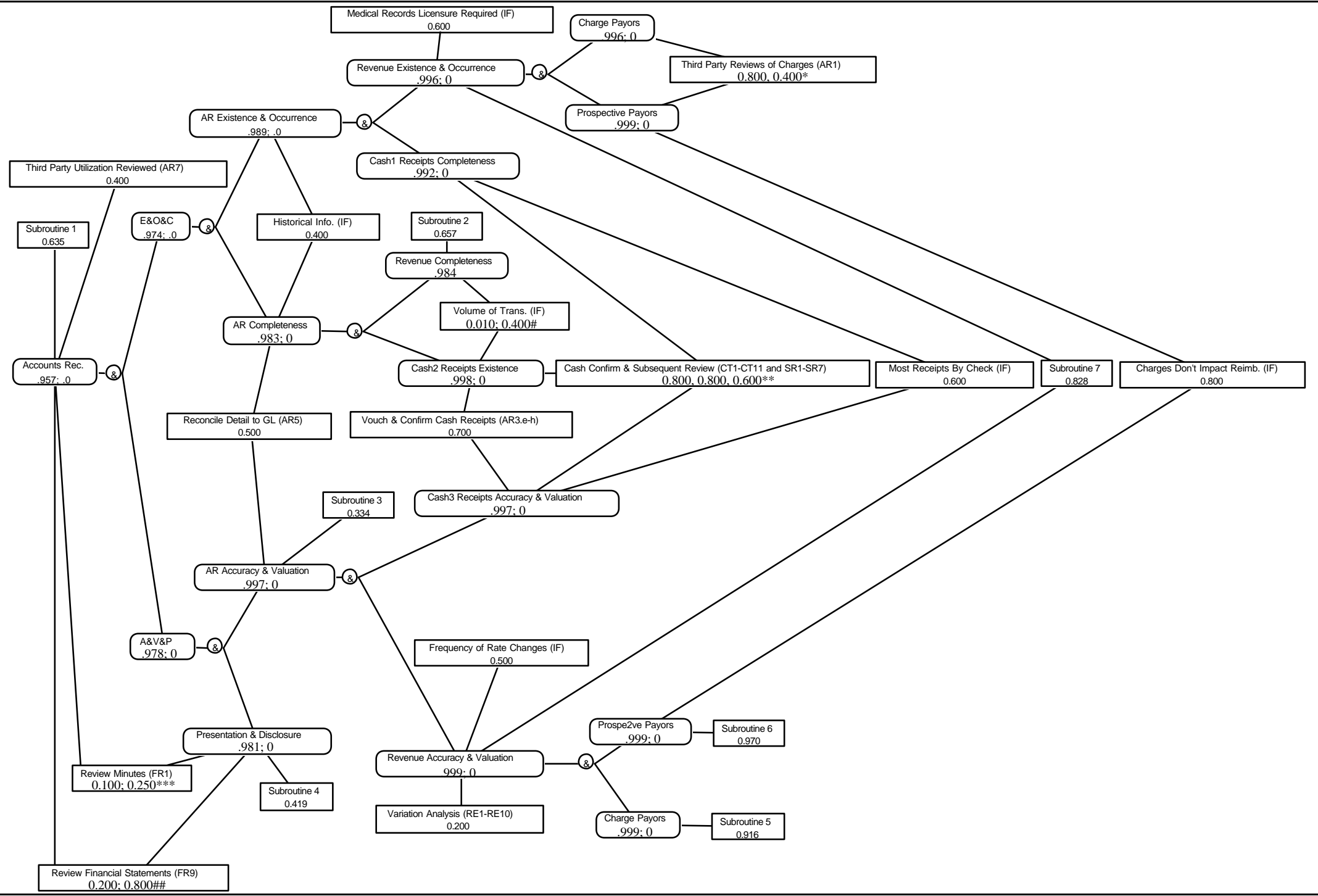

*0.8, and 0.4 levels of support to 'Prospective Payors' and 'Charge Payors', respectively, that they are met. Similarly the following levels of support imply that the corresponding objective has been met: **0.8, 0.8, and 0.6, respectively, for 'Cash Receipts Completeness', 'Cash Receipts Existence', and 'Cash Receipts Accuracy \& Valuation'; *** 0.1 , and 0.25 , respectively, for 'Accounts Rec.', and 'Presentation and Disclosure'; \#0.01, and 0.4, respectively for 'Revenue Completeness', and 'Cash Receipts Existence'; \#\#0.2, and 0.8, respectively, for 'Accounts Rec.', and 'Presentation and Disclosure'. 


\section{Figure 2}

Subroutines 1-3 used in Figure 1. (The evidence boxes contain the corresponding procedure(s) with the abbreviated name(s) in a parenthesis as listed in the audit program.

IF stands for inherent factors.)
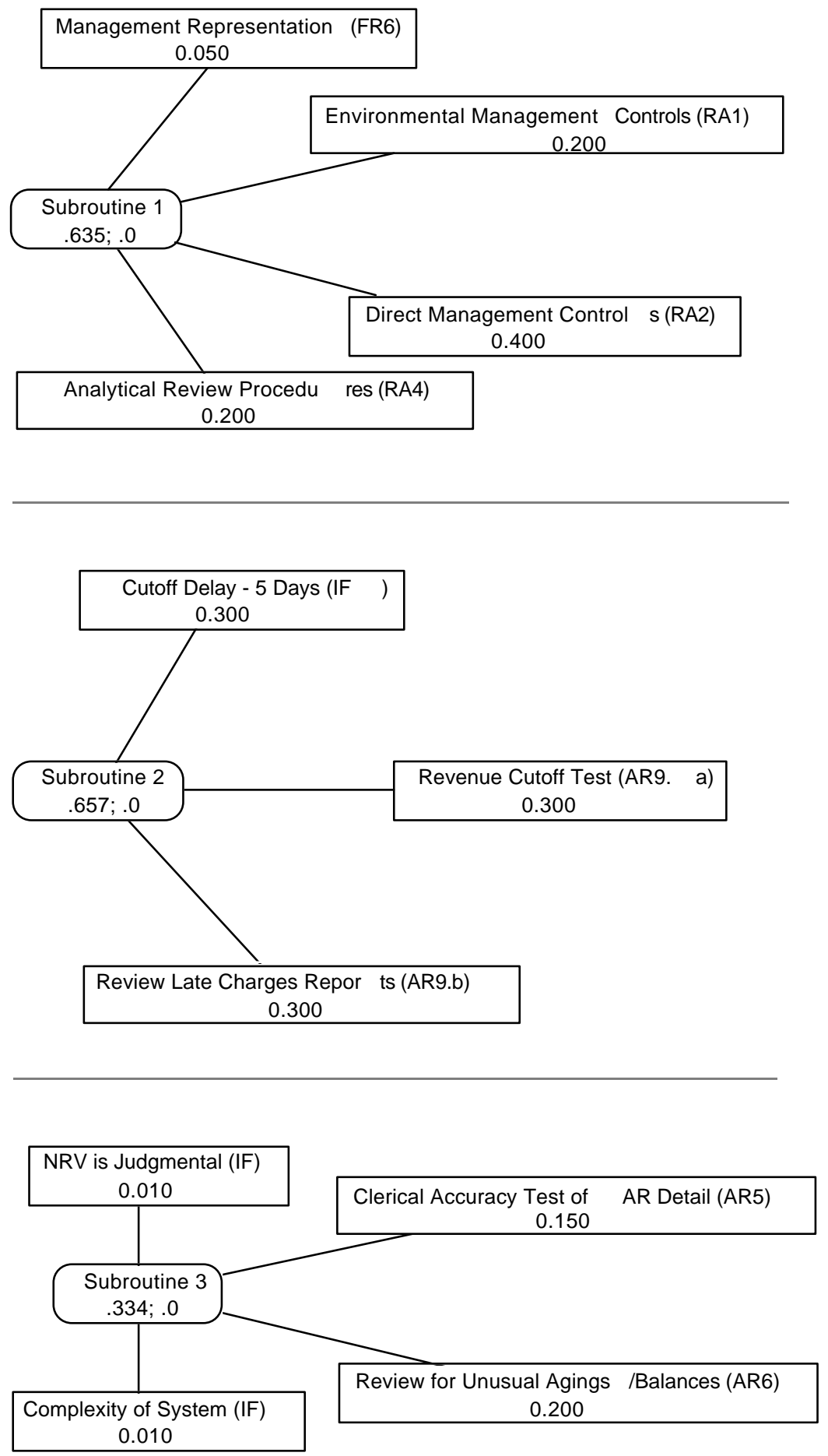


\section{Figure 3}

Subroutines 4 and 5 used in Figure 1. (The evidence boxes contain the corresponding procedure(s) with the abbreviated name(s) in a parenthesis as listed in the audit program.

IF stands for inherent factors. An item of evidence with a dotted boundary indicates that the corresponding procedure(s) is (are) either not performed or not relevant.)
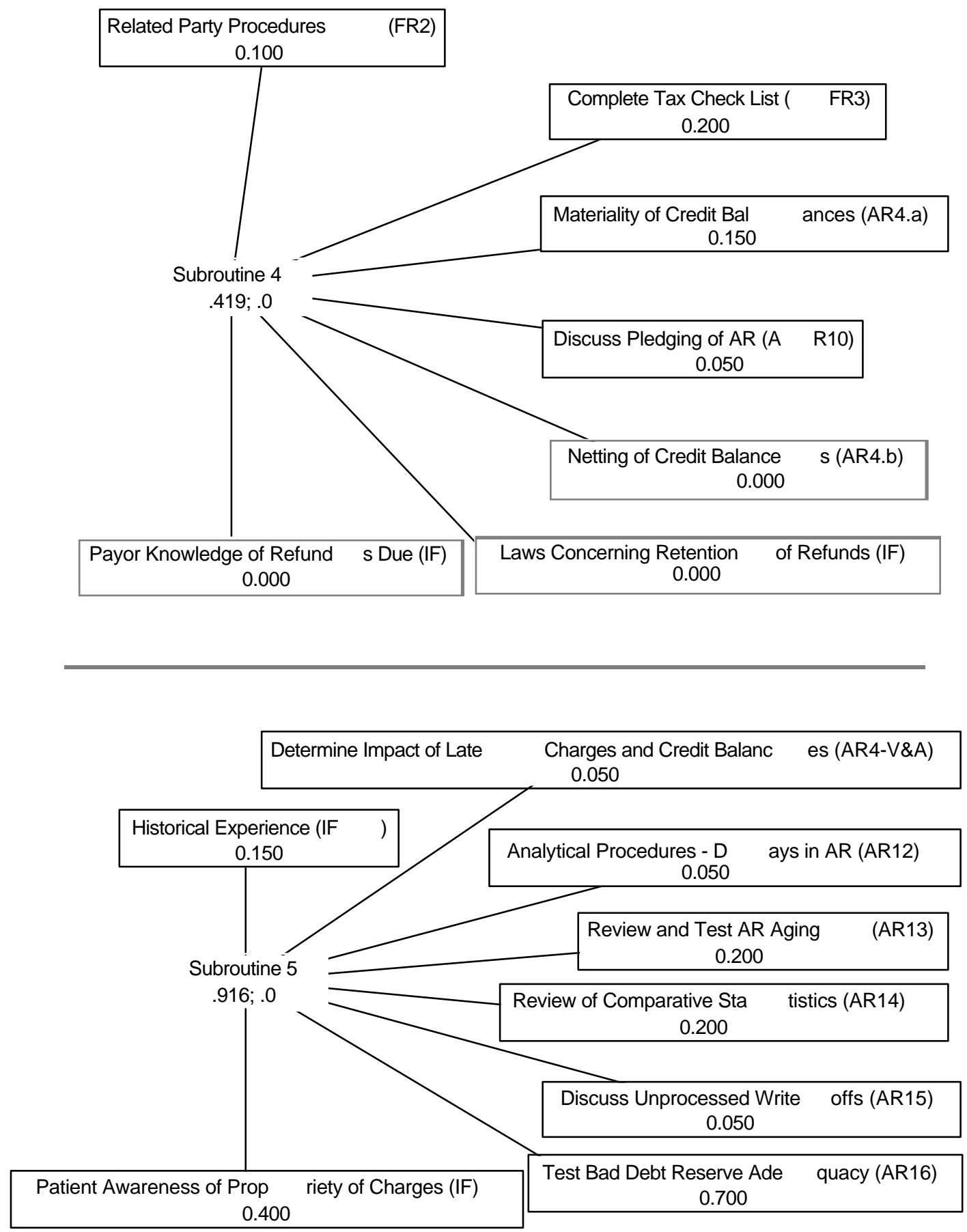


\section{Figure 4}

Subroutines 6 and 7 used in Figure 1. (The evidence boxes contain the corresponding procedure(s) with the abbreviated name(s) in a parenthesis as listed in the audit program.

IF stands for inherent factors.)
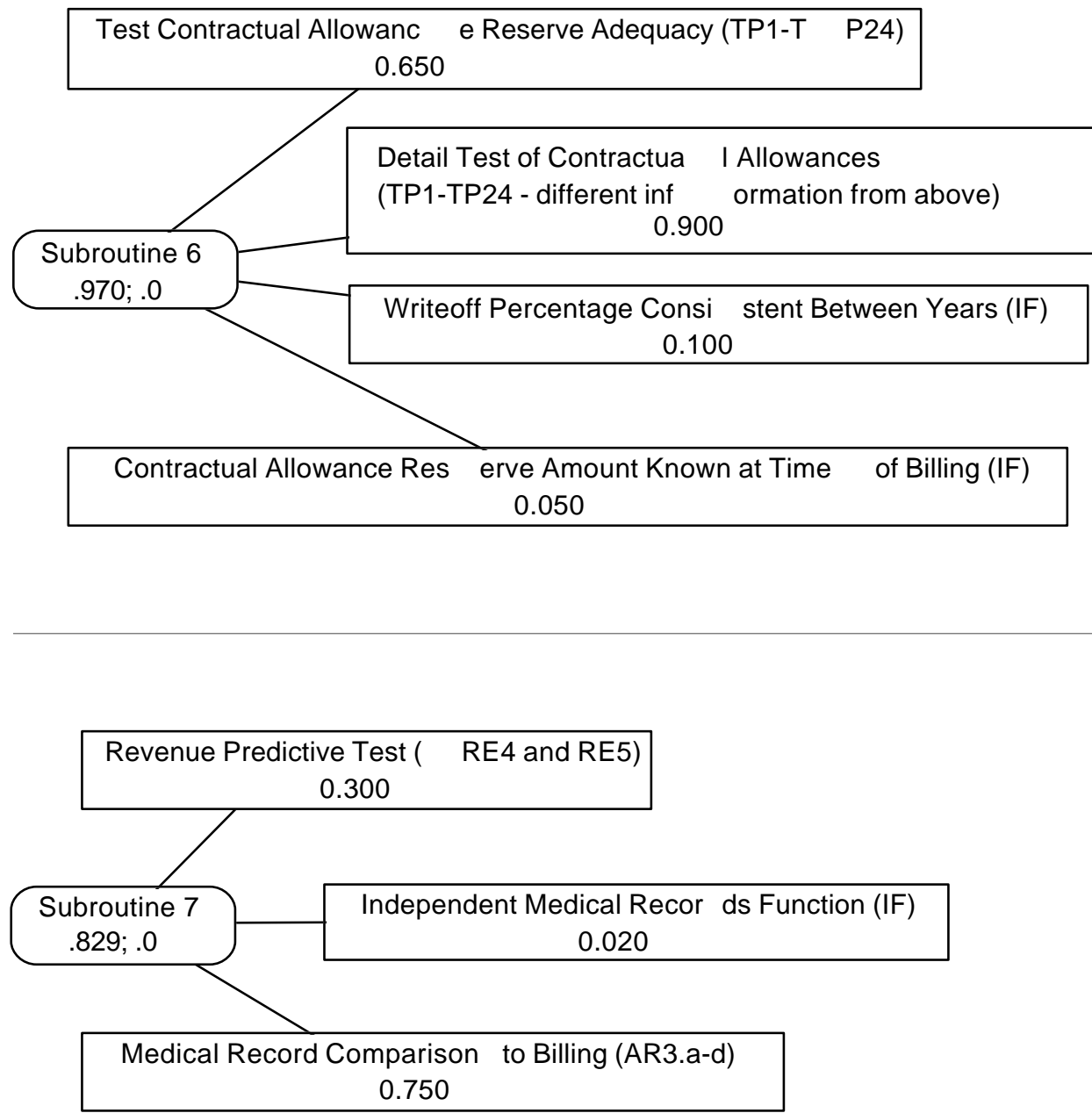


\section{Figure 5}

Effects of Positive Evidence at the Account Level on Audit Objectives of the Account

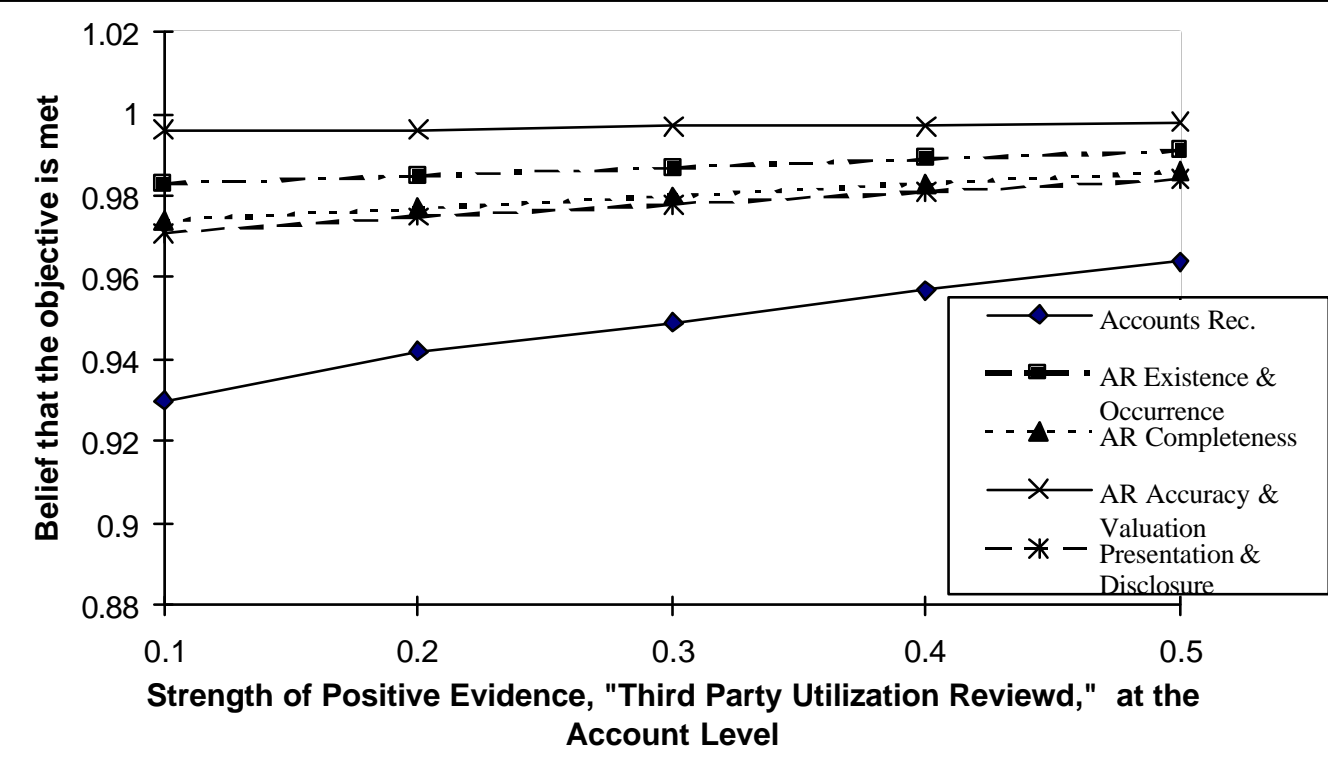




\section{Figure 6}

Effects of Negative Evidence at the Account Level on Audit Objectives of the Account

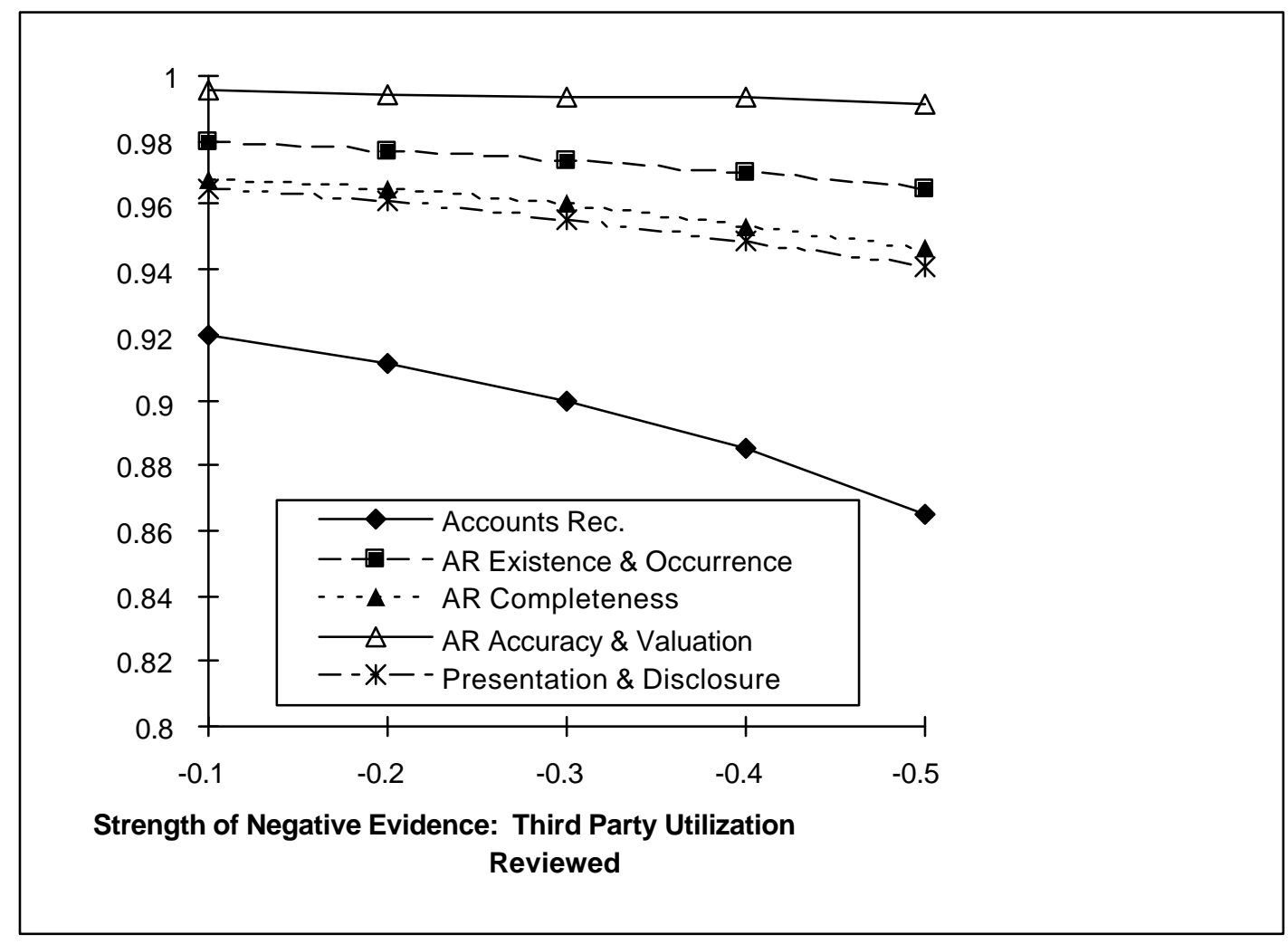




\section{Figure A1}

Creation of Variable Nodes and an 'And' Relationship.

Panel (a)

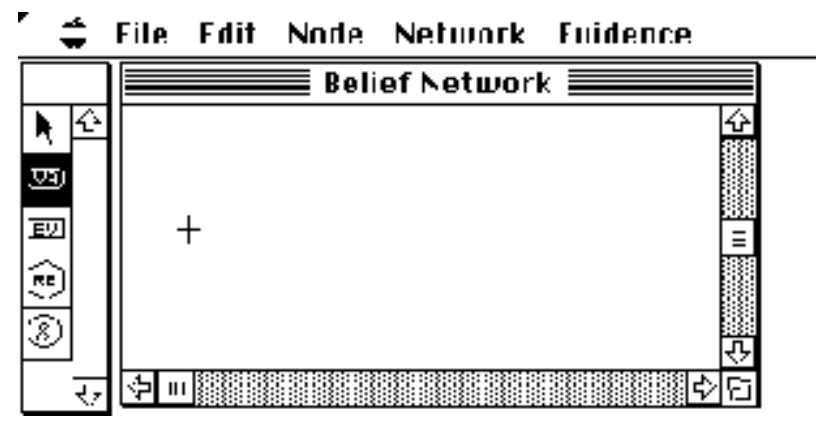

Panel (c)

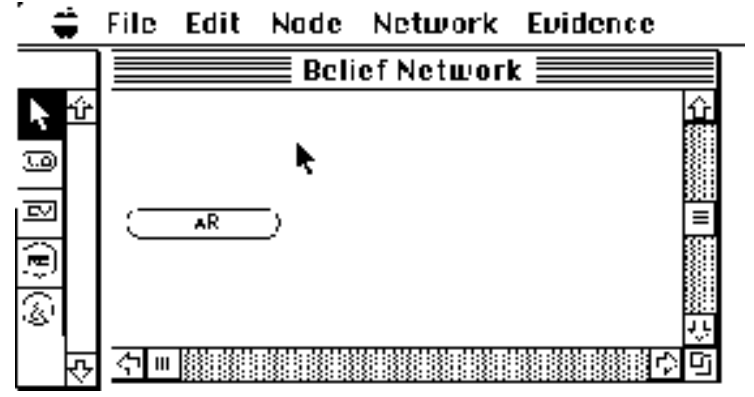

Panel (b)

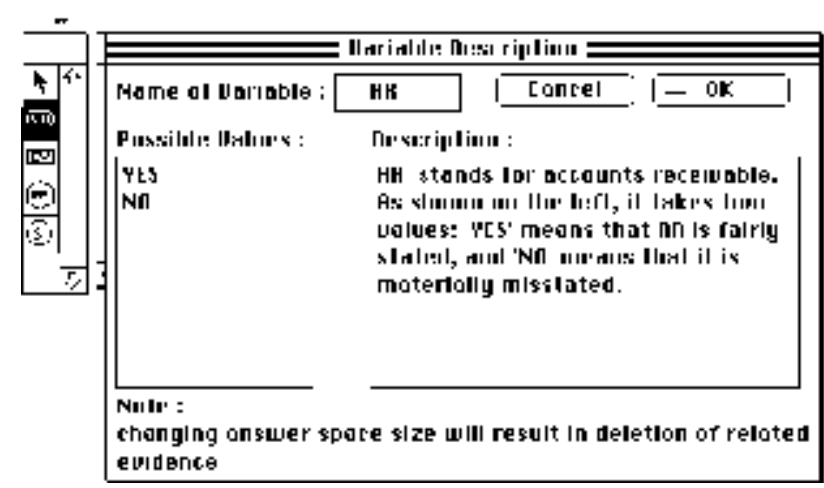

Panel (d)

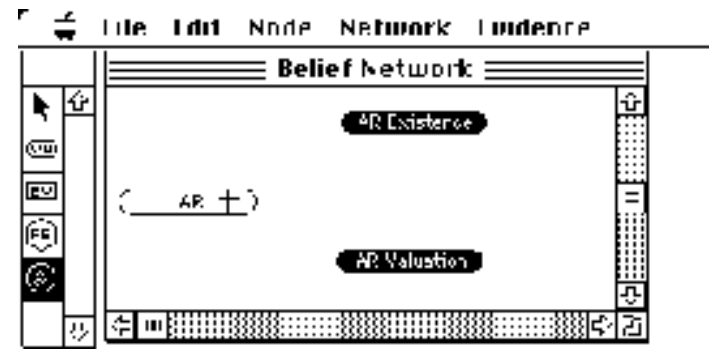

Panel (e)

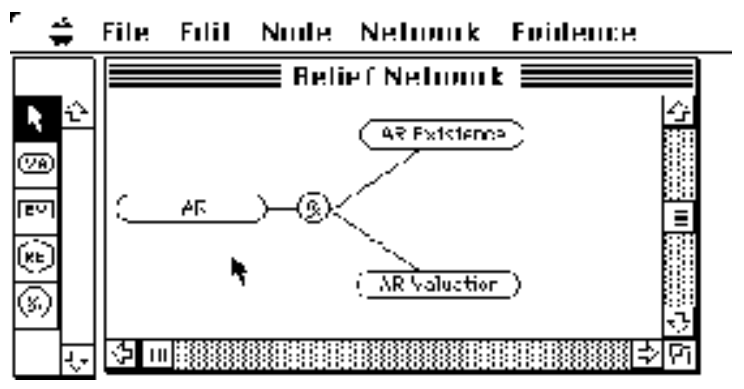




\section{Figure A2}

Variables with an 'OR' Relationship.

Panel (a)

Panel (c)

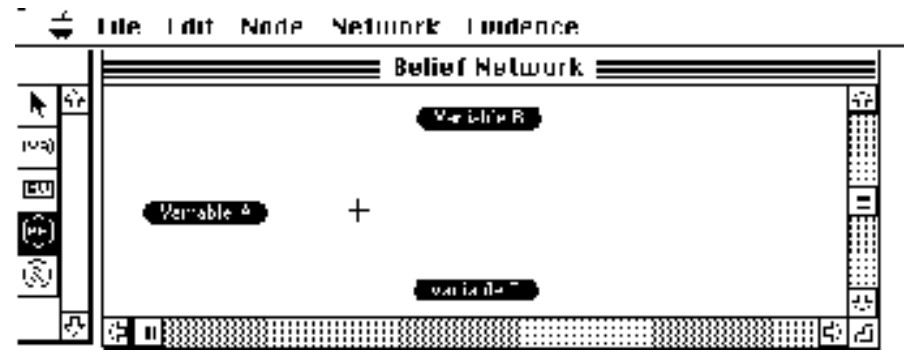

* I lle Lalt Node Me1worx Luldence

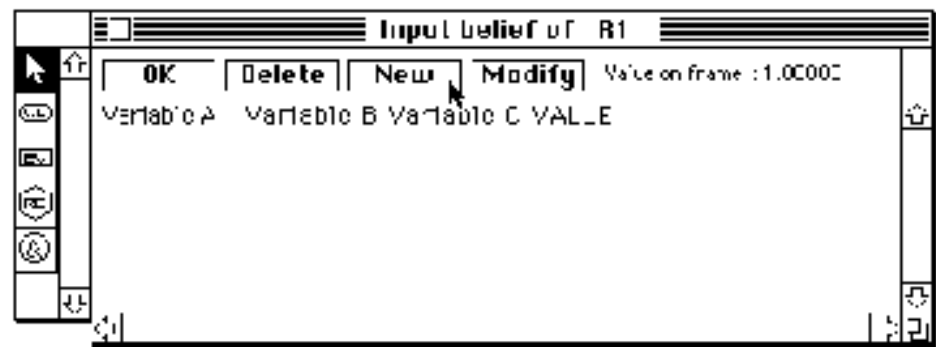

Panel (e)

* Flle Edlt Nade vetwork Euldence

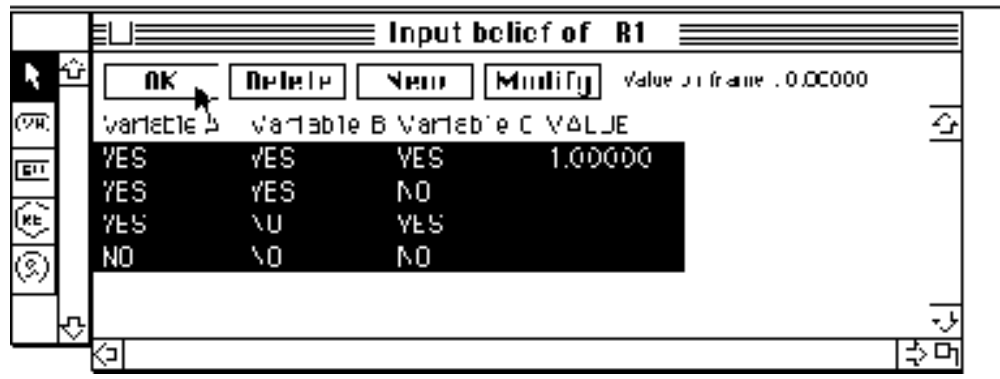

Panel (b)

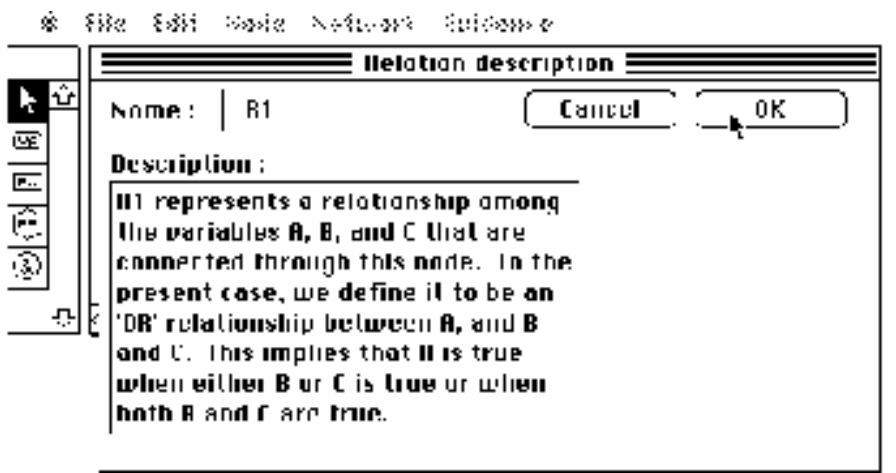

Panel (d)

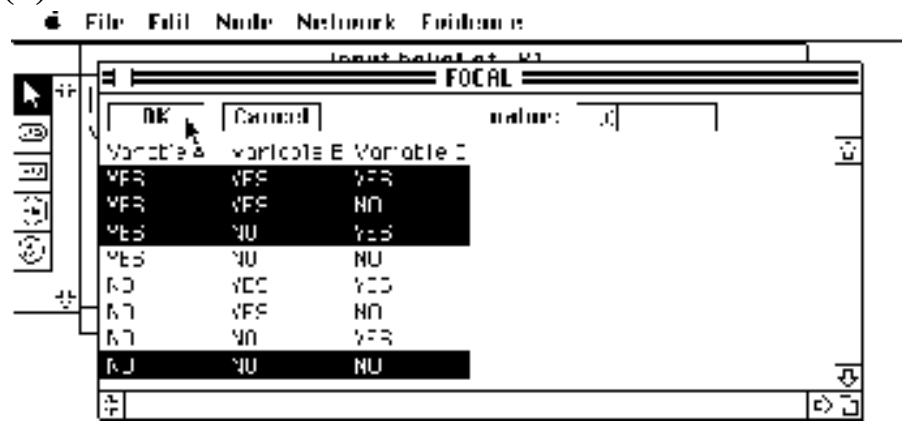

Panel (f)

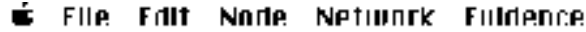
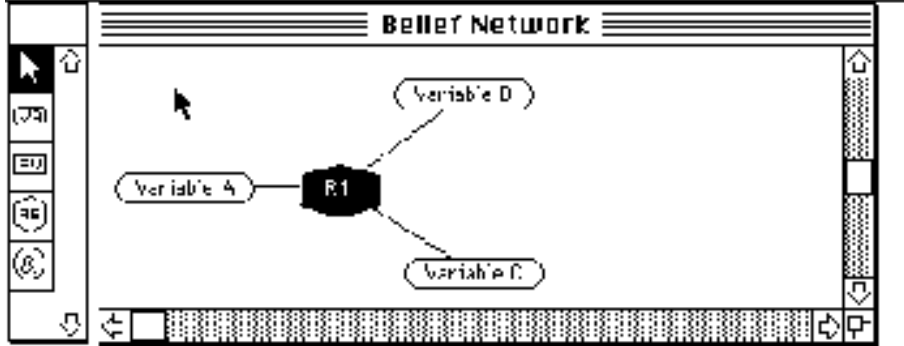